\title{
MODELAGEM ANALÍTICA DO PERFIL DE TEMPERATURA NO SOLO
}

\author{
Elimoel Abrão Elias
}

Tese apresentada à Escola Superior de Agricultura "Luiz de Queiroz", Universidade de São Paulo, para obtenção do título de Doutor em Agronomia, Área de Concentração: Física do Ambiente Agrícola.

PIR A C I C A B A

Estado de São Paulo - Brasil

Maio - 2004 


\title{
MODELAGEM ANALÍTICA DO PERFIL DE TEMPERATURA NO SOLO
}

\author{
Elimoel Abrão Elias
}

Licenciado em Física

Orientador: Prof. Dr. QUIRIJN DE JONG VAN LIER

Tese apresentada à Escola Superior de Agricultura "Luiz de Queiroz", Universidade de São Paulo, para obtenção do título de Doutor em Agronomia, Área de Concentração: Física do Ambiente Agrícola.

PIRACICABA

Estado de São Paulo - Brasil

Maio - 2004 
Dados Internacionais de Catalogação na Publicação (CIP)
DIVISÃO DE BIBLIOTECA E DOCUMENTAÇÃO - ESALQ/USP

Elias, Elimoel Abrão

Modelagem analítica do perfil de temperatura no solo / Elimoel Abrão Elias. - Piracicaba, 2004.

$67 \mathrm{p}$.

Tese (doutorado) - - Escola Superior de Agricultura Luiz de Queiroz, 2004.

Bibliografia.

1. Modelo analítico 2. Propriedades térmicas 3. Temperatura do solo I. Título

CDD 631.436

"Permitida a cópia total ou parcial deste documento, desde que citada a fonte - O autor" 
A meu irmão, Elias, e minha mãe, Dirce, dedico. 


\section{AGRADECIMENTOS}

Ao Prof. Dr. Quirijn de Jong van Lier, pela orientação e por conceder-me a oportunidade de desenvolver este trabalho.

A CAPES pela concessão de bolsa de estudos.

Aos demais professores da ESALQ, aos meus colegas, e a todas as pessoas que, de maneira direta ou indireta, contribuíram para a realização deste trabalho. 


\section{SUMÁRIO}

Página

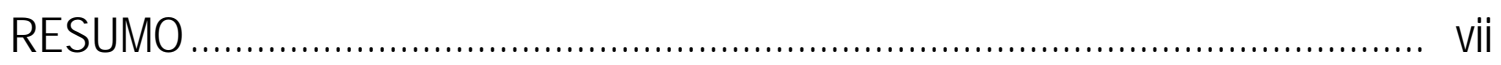

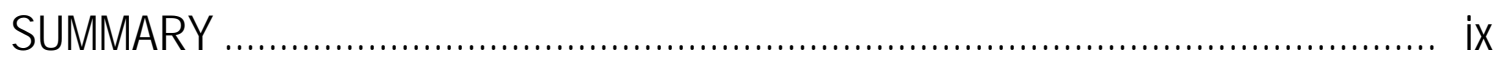

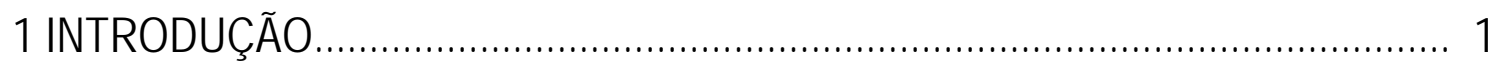

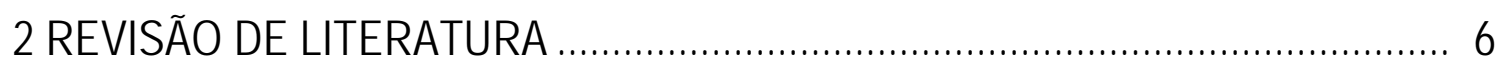

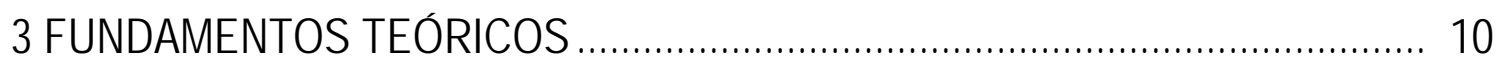

3.1 A EQUAÇÃO DO FLUXO LINEAR DE CALOR NO SOLO ................................................... 10

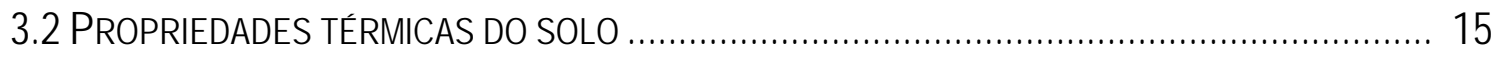

3.3 APLICAÇÃO DA EQUAÇÃO DO FLUXO LINEAR DE CALOR NO SOLO .................................. 17

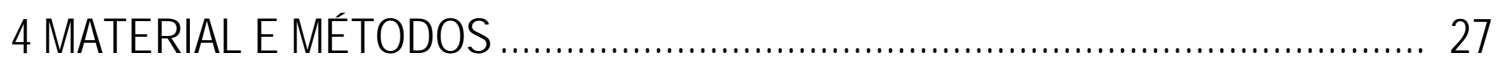

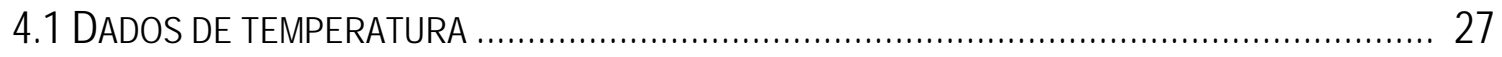

4.2 Modelo ANALÍtICO PARA TEMPERATURA DO PERFIL DO SOLO ..................................... 27

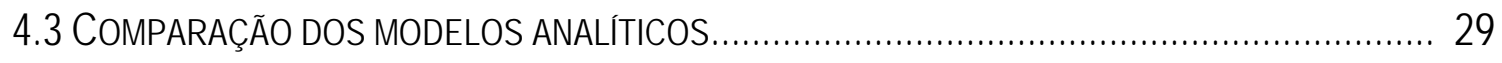

4.3.1 Profundidades de amortecimento ....................................................................... 29

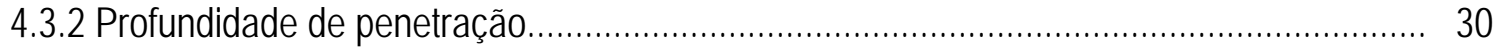

4.3.3 Erro quadrático médio ………….................................................................... 31 
4.3.4 Erro quadrático médio na forma de uma integral.................................................... 33

5 RESULTADOS E DISCUSSÃO .................................................................. 46

5.1 PROFUNDIDADE DE AMORTECIMENTO ......................................................... 46

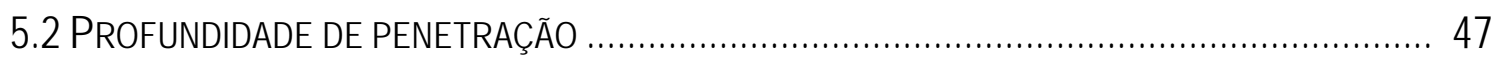

5.3 CoMPARAÇÃO PELO EQM ................................................................................ 47

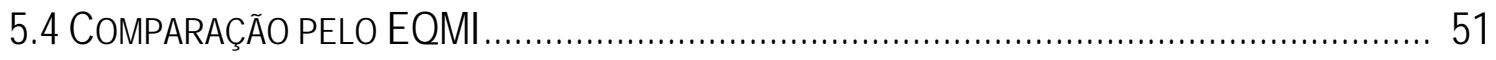

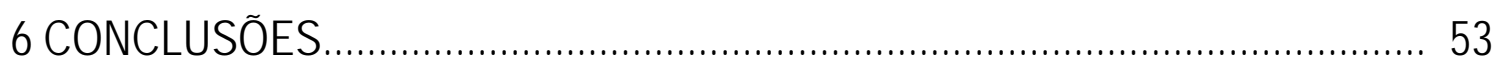

REFERÊNCIAS BIBLIOGRÁFICAS .............................................................. 55

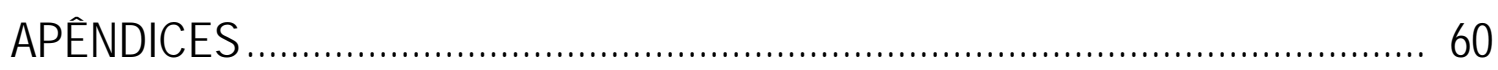




\title{
MODELAGEM ANALÍTICA DO PERFIL DE TEMPERATURA NO SOLO
}

\author{
Autor: ELIMOEL ABRÃO ELIAS \\ Orientador: Prof. Dr. QUIRIJN DE JONG VAN LIER
}

\section{RESUMO}

A temperatura do solo influencia a maioria dos processos físicos, químicos e biológicos que ocorrem no solo. O modelo analítico exponencial-senoidal em uma dimensão descreve razoavelmente bem a temperatura no solo, $\mathrm{T}\left({ }^{\circ} \mathrm{C}\right)$, como função do tempo, $\mathrm{t}(\mathrm{s})$, e da profundidade, $\mathrm{z}(\mathrm{m}), 0 \leq \mathrm{z}<\infty$. A temperatura da superfície pode ser representada pela soma de duas senóides, uma relacionada com variações de temperatura anuais, outra com variações diárias, cada uma tendo uma amplitude constante. Uma correção para a variação temporal de amplitude diária é aqui introduzida. A equação do calor é resolvida analiticamente, com pouco aumento em complexidade em relação à solução tradicional. Predições de temperatura obtidas pela nova solução analítica foram comparadas com predições obtidas da solução usual, que trata a amplitude diária como constante. Para comparar as predições, foram necessários valores experimentais de certos parâmetros que aparecem nestas equações; foi suficiente usar valores típicos, obtidos na literatura. Predições são comparadas utilizando quatro conceitos: (i) profundidade de amortecimento, D; (ii) profundidade de penetração, $\mathrm{z}_{\mathrm{M}}$; (iii) erro quadrático médio (EQM); e (iv) erro quadrático médio na forma de uma integral (EQMI). O conceito de $\mathrm{z}_{\mathrm{M}}$ foi aqui introduzido, acompanhado por uma equação simples que permite calcular qual é a profundidade $z_{m}$ tal que, se temperatura $T\left(z_{M}, t\right)$ for aproximada como $\mathrm{T}_{\mathrm{a}}$ (valor médio da temperatura ao longo do ano, em $\mathrm{z}_{\mathrm{M}}$ ), o erro em tal aproximação será igual ou menor um certo valor previamente definido, por exemplo, de 
0,1 ${ }^{\circ} \mathrm{C}$. O conceito de EQMI, também introduzido nesta tese, substitui o somatório que aparece no EQM por uma integral definida, e serve para comparar dois modelos analíticos, o que era o caso desta tese. Valores de $\mathrm{D}$ e $\mathrm{z}_{\mathrm{M}}$ mostram que a correção é desprezível para z > 0,6 m. Valores de EQM mostram que a correção é considerável para $\mathrm{z}=0,1 \mathrm{~m}$. Nesta profundidade, o valor máximo foi $\mathrm{EQM}=0.30{ }^{\circ} \mathrm{C}$ para dias inteiros, e $\mathrm{EQM}=0.29{ }^{\circ} \mathrm{C}$ para meses inteiros. Valores de EQMI foram praticamente iguais aos valores de EQM. Para qualquer profundidade a correção introduzida, ainda que considerável, é pequena. Entretanto, a única informação adicional requerida para aplicar a equação nova é a informação de variação temporal da amplitude diária. Desta forma, pode-se sugerir que a nova equação seja preferida, quando esta informação esteja facilmente disponível a partir de dados experimentais. 


\section{ANALYTICAL SOIL-TEMPERATURE MODEL}

Author: ELIMOEL ABRÃO ELIAS

Adviser: Prof. Dr. QUIRIJN DE JONG VAN LIER

\section{SUMMARY}

Soil temperature influences many physical, chemical and biological processes that occur in soil. The exponential-sinusoidal one-dimensional analytical model reasonably describes soil temperature, $\mathrm{T}\left({ }^{\circ} \mathrm{C}\right)$, as a function of time, $\mathrm{t}(\mathrm{s})$, and depth, $\mathrm{z}$ (m), $0 \leq \mathrm{z}<\infty$. Surface temperature may be represented by the sum of two sinusoids, one related to annual and the other to daily temperature variations, each one having constant amplitude. A correction for the temporal variation of daily amplitude is introduced here. The heat equation is solved analytically, with minimal increase in complexity compared to the traditional solution. Temperature predictions obtained from the novel analytical solution are compared with predictions from the usual solution that treats the daily amplitude as a constant. Comparisons demanded experimental parameters, which were obtained from scientific literature. Predictions are compared using four concepts: (i) damping depth, D; (ii) penetration depth, $\mathrm{z}_{\mathrm{M}}$; (iii) root mean squared error (RMSE); and (iv) root mean squared error defined by a definite integral (RMSEI). The concept of $\mathrm{z}_{\mathrm{M}}$ was introduced here, through a simple equation, which allows calculation of the depth $\mathrm{z}_{\mathrm{m}}$, at which $\mathrm{T}\left(\mathrm{z}_{\mathrm{M}}, \mathrm{t}\right)$ can be approximated to $\mathrm{T}_{\mathrm{a}}$ (average annual value of soil temperature at $\mathrm{z}_{\mathrm{M}}$ ). The concept of RMSEI was also introduced here, and replaces a sum by a definite integral. The RMSEI can be used to compare analytical models, as it was the case here. Values of $\mathrm{D}$ and $\mathrm{z}_{\mathrm{M}}$ show that the correction is 
negligible for $\mathrm{z}>0,6 \mathrm{~m}$. Values of RMSE show that the correction is considerable for $\mathrm{z}=0,1 \mathrm{~m}$. For individual days, at a depth $\mathrm{z}=0,1 \mathrm{~m}$, the maximum value was RMSE $=0.30{ }^{\circ} \mathrm{C}$; for whole months, the maximum value was $\mathrm{RMSE}=0.29{ }^{\circ} \mathrm{C}$. RMSEI values were practically the same as RMSE values. The correction introduced here was small at all depths. However, the only additional information required to apply the novel equation is information on temporal variation of daily amplitude, so this equation should be preferred when such data are readily available. 


\section{INTRODUÇÃO}

Muitos processos físicos, químicos e biológicos que ocorrem no solo são influenciados pela temperatura. Assim, tem sido objeto de estudo encontrar a função $\mathrm{T}=\mathrm{T}(\mathrm{z}, \mathrm{t})$ que descreve a temperatura do perfil do solo, onde $\mathrm{T}\left({ }^{\circ} \mathrm{C}\right)$ é a temperatura do solo em um tempo $\mathrm{t}(\mathrm{s})$ e profundidade $\mathrm{z}(\mathrm{m}), 0 \leq \mathrm{z}<\infty$. Uma forma de encontrar esta função é pela modelagem do movimento da energia no solo, baseando-se em leis físicas e em alguns parâmetros empíricos. Van Wijk \& de Vries (1963) propuseram um modelo analítico, unidimensional e vertical. Neste modelo, parte-se do pressuposto de que a temperatura do solo satisfaz a equação do fluxo linear do calor:

$$
\frac{\partial T}{\partial t}=K \frac{\partial^{2} T}{\partial z^{2}}
$$

onde $\mathrm{K}\left(\mathrm{m}^{2} \mathrm{~s}^{-1}\right)$ é a difusividade térmica, que é considerada constante no tempo e em profundidade. Maiores detalhes sobre o significado físico desta equação encontram-se na seção 3.1. Além disso, duas condições de contorno devem ser satisfeitas. A primeira é:

$T(0, t)=T_{a}+A \sin (\omega t+\varphi)$

a qual indica que a temperatura superficial varia senoidalmente com o tempo, possuindo uma média temporal $\mathrm{T}_{\mathrm{a}}\left({ }^{\circ} \mathrm{C}\right)$, amplitude $\mathrm{A}\left({ }^{\circ} \mathrm{C}\right)$, freqüência angular $\omega\left(\mathrm{rad} \mathrm{s}^{-1}\right) \mathrm{e}$ constante de fase $\varphi(\mathrm{rad})$. A segunda condição de contorno é: 
$\lim _{z \rightarrow \infty} T(z, t)=T_{a}$

indicando que muito longe da superfície, o solo permanece na temperatura média independente do tempo.

A solução da eq. [1] que também satisfaz as condições de contorno dadas pelas eq. [2] e [3] é:

$T(z, t)=T_{a}+A \exp (-z / D) \sin (\omega t-z / D+\varphi)$

onde $\mathrm{D}(\mathrm{m})$ é a profundidade de amortecimento, definida como:

$D=\sqrt{\frac{2 K}{\omega}}$

A dedução da solução acima é apresentada na seção 3.3 desta tese. Pode-se facilmente confirmar que a eq. [4] é de fato a solução, substituindo a mesma nas eq. [1], [2] e [3]. A eq. [4] pode ser usada tanto para descrever variações anuais de temperatura, como variações diárias. Para o caso de variações diárias, as variáveis $T_{a}, A, D, \omega$ e $\varphi$ são substituídas por $T_{a d}, A_{d}, D_{d}, \omega_{d}$ e $\varphi_{d}$, e para o caso de variações anuais, por $T_{a y}$, $\mathrm{A}_{\mathrm{y}}, \mathrm{D}_{\mathrm{y}}, \omega_{\mathrm{y}} \mathrm{e} \varphi_{\mathrm{y}}$, onde os subscritos "d" e "y" indicam diário e anual, respectivamente. Entretanto, para descrever ambas as variações, uma outra equação, eq. [10], deve ser utilizada (Van Wijk \& de Vries, 1963; Steenhuis \& Walter, 1986), a qual será aqui deduzida. Modificações da eq. [2] levam às seguintes condições de contorno:

$$
\begin{aligned}
& T(0, t)=T_{a d}+A_{d} \sin \left(\omega_{d} t+\varphi_{d}\right) \\
& T(0, t)=T_{a y}+A_{y} \sin \left(\omega_{y} t+\varphi_{y}\right)
\end{aligned}
$$


$\mathrm{Na}$ eq. [6] a média diária da temperatura superficial, $\mathrm{T}_{\mathrm{ad}}$, é considerada constante durante todo o período de interesse, que deve ser relativamente curto, por exemplo, dias ou semanas. $\mathrm{Na}$ verdade, $\mathrm{T}_{\mathrm{ad}}$ é dependente do tempo e, geralmente, é mais alta em um dia de inverno do que em um dia de verão. Assim, para períodos longos, é necessário considerar a dependência temporal de $\mathrm{T}_{\mathrm{ad}}$, que pode ser obtida usando a eq. [7]. $\mathrm{Na}$ eq. [7], $\mathrm{T}(0, \mathrm{t})$ é (aproximadamente) a média da temperatura superficial para o dia correspondente ao tempo t; tal que a eq. [7] pode ser escrita como:

$\mathrm{T}_{\mathrm{ad}}(0, \mathrm{t})=\mathrm{T}_{\mathrm{ay}}+\mathrm{A}_{\mathrm{y}} \sin \left(\omega_{\mathrm{y}} \mathrm{t}+\varphi_{\mathrm{y}}\right)$

Substituindo eq. [8] na eq. [6], obtém-se:

$T(0, t)=T_{a y}+A_{y} \sin \left(\omega_{y} t+\varphi_{y}\right)+A_{d} \sin \left(\omega_{d} t+\varphi_{d}\right)$

$\mathrm{Na}$ eq. [9], o termo [ $\left.\mathrm{T}_{\mathrm{ay}}+\mathrm{A}_{\mathrm{y}} \sin \left(\omega_{\mathrm{y}} \mathrm{t}\right)\right]$ é (aproximadamente) a temperatura média para o dia correspondente ao tempo t, e a temperatura diária oscila em torno desta média de acordo com o termo [ $\left.A_{d} \sin \left(\omega_{d} t+\varphi_{d}\right)\right]$. Assim, a eq. [9] pode ser vista como uma correção para a eq. [6], levando em conta a variação sazonal de $T_{\text {ad }}$. Uma combinação linear de soluções independentes da eq. [1] é também uma solução da eq. [1] (conforme será visto na seção 3.3 desta tese). A solução do problema dado pelas eq. [1], [3] e [9] é:

$$
\begin{aligned}
T(z, t)=T_{a y}+A_{y} \exp \left(-z / D_{y}\right) \sin \left(\omega_{y} t-z / D_{y}+\varphi_{y}\right)+ \\
\quad A_{d} \exp \left(-z / D_{d}\right) \sin \left(\omega_{d} t-z / D_{d}+\varphi_{d}\right)
\end{aligned}
$$

que foi apresentada por Van Wijk \& de Vries (1963).

O modelo acima descrito é uma simplificação de condições reais de campo, uma vez que $\mathrm{K}$ em geral não é constante em profundidade e no tempo, e as condições de contorno podem ser apenas satisfeitas como uma primeira aproximação. A condição de 
contorno dada pela eq. [9] não leva em conta mudanças resultantes de variações nas condições meteorológicas, embora esta aproximação possa ser razoável para médias calculadas a partir de séries longas de observações (Van Wijk \& de Vries, 1963, p. 102, 113). Apesar de tais simplificações, o modelo tem sido bastante útil porque ele fornece um discernimento físico da transferência de calor no solo, fornece um meio para verificação de modelos numéricos, e também fornece uma teoria permitindo a estimativa de propriedades térmicas do solo e de fluxo de calor no solo (Kluitenberg \& Horton, 1990, p. 1197). Assim, modelos simplificados, ainda que inexatos, são muito importantes. Além disso, podem ser corrigidos gradualmente, atingindo níveis de complexidade cada vez maiores.

Embora o modelo de Van Wijk \& de Vries (1963) leve em conta as variações temporais da temperatura média diária, ele assume que a amplitude diária é constante no tempo. É um fato conhecido que a amplitude diária não é necessariamente constante. Assim, a constante $A_{d}$ utilizada nas eq. [9] e [10] é na verdade uma média anual da amplitude diária. Elias et al (2004) ajustaram dados de amplitude diária, $\mathrm{C}(\mathrm{t})\left({ }^{\circ} \mathrm{C}\right)$, de temperatura superficial e quase-superficial do solo, a uma função senoidal do tempo:

$C(t)=A_{d}+B \sin \left(\omega_{b} t+\beta\right)$

onde $\mathrm{B}\left({ }^{\circ} \mathrm{C}\right)$ é uma constante, relacionada com a variação temporal da amplitude diária em torno de seu valor médio, $A_{d} ; \omega_{b}\left(\mathrm{rad} \mathrm{s}^{-1}\right)$ é a freqüência angular, e $\beta(\mathrm{rad})$ é uma constante de fase. Maiores detalhes sobre isto se encontram no Apêndice 1 desta tese. $\mathrm{O}$ objetivo geral deste estudo foi aperfeiçoar o modelo analítico de Van Wijk \& de Vries (1963), corrigindo ainda mais a condição de contorno na superfície, para que o modelo pudesse levar em conta a variação temporal da amplitude diária da temperatura superficial do solo, dada pela eq. [11]. Este objetivo geral foi dividido em dois objetivos específicos: (i) deduzir uma nova solução analítica para a eq. [1], para o caso em que a condição de contorno dada pela eq. [9] tem o valor constante $A_{d}$ substituído pela 
amplitude diária dependente do tempo, conforme eq. [11] e (ii) comparar predições da solução nova com predições da eq. [10], numérica e analiticamente. 


\section{REVISÃO DE LITERATURA}

A teoria da condução de calor em sólidos foi tratada em detalhes por Carslaw \& Jaeger (1959). Nesta obra também é tratado o problema específico da transferência de calor no solo, embora não seja o assunto principal. Trata, por exemplo, da solução da equação do fluxo linear do calor para um sólido semi-infinito, com temperatura superficial sendo uma função senoidal do tempo, supondo a difusividade térmica constante. Ou seja, trata de uma modelagem analítica para a transferência de calor no solo. É também demonstrado que esta modelagem permite a determinação da difusividade térmica do solo. Esta teoria é também apresentada por Van Wijk (1963), porém focalizando aplicações para o solo agrícola. Parte desta teoria foi aqui mostrada no capítulo 1. Carslaw \& Jaeger (1959) reconhecem que fazem um tratamento apenas aproximado do problema da transferência de calor no solo, uma vez que esta é altamente afetada pela presença de água, o que afeta a difusividade térmica. Van Wijk (1963) expande a modelagem analítica para situações em que a difusividade térmica varia com o tempo. Também considera situações em que a temperatura superficial do solo desviase da periodicidade, bem como situações periódicas em solo estratificado. Entretanto, as situações consideradas são bastante específicas, de forma que, quando se consideram situações arbitrárias de campo, o tratamento continua sendo apenas aproximado. Dentre autores subseqüentes que utilizaram a modelagem analítica para determinação de campo da difusividade térmica do solo encontram-se Thunholm (1988) e Horton et al. (1983); em laboratório, encontram-se Jackson \& Kirkham (1958). Em estudos de laboratório, a difusividade térmica pode ser medida com maior exatidão, porque se podem controlar a periodicidade de entrada de energia na superfície do solo, e também a homogeneidade do solo. 
Sinclair \& Seligman (1996, p. 702), referindo-se a modelos de crescimento de culturas, afirmam: "Excessive complexity will obscure, and even distort whatever heuristic benefit may be gained about crop performance at the desired level of interest." Pode-se expandir e generalizar isto em termos de modelagem em geral. Um aumento da complexidade do modelo o tornará mais próximo da realidade, mas há um preço a ser pago, o qual é uma perda de discernimento físico. Assim, modelos simples, embora inexatos, são muito importantes. Modelagem deve ser feita em vários níveis de complexidade, não somente no nível mais alto. Cada nível tem suas próprias vantagens, sendo mais adequado para um ou outro propósito particular. Modelos analíticos simples para a temperatura do solo, como aqueles citados acima, continuam sendo importantes, embora atualmente existam modelos mais complexos, tanto analíticos como numéricos.

Massman (1993) e Kluitenberg \& Horton (1990) enfatizam o fato de que os modelos analíticos, embora sejam válidos apenas como aproximações, têm sido muito úteis por fornecerem um discernimento físico do processo de transferência no solo, o que está em perfeita concordância com as idéias de Sinclair \& Seligman (1996) acima mencionadas. A modelagem descrita por Van Wijk \& de Vries (1963), reproduzida na Introdução desta tese, é freqüentemente mencionada em livros-texto de física do solo, provavelmente porque o discernimento físico e a simplicidade têm valor educacional considerável, além da utilidade científica. Alguns exemplos são Reichardt \& Timm (2004), Campbell \& Norman (1998), Hanks (1992), Jury et al. (1991), Richter (1987) e Kirkham \& Powers (1972).

Diversos autores trabalharam com modelagem analítica de maior complexidade. Kluitenberg \& Horton (1990) desenvolveram um modelo analítico bidimensional. Parton \& Logan (1981) observaram que a temperatura superficial do solo é mais bem descrita por uma função senóide truncada para predizer a temperatura durante o dia, e uma função exponencial para predizer a temperatura à noite. Massman (1993) estudou algumas soluções analíticas aproximadas para a equação do fluxo linear do calor, para o caso em que a difusividade térmica não é constante. Este autor observa que, infelizmente, não existe uma solução analítica exata para uma difusividade térmica que 
seja uma função arbitrária do tempo e profundidade. Ou seja, modelos analíticos sempre são uma aproximação, em certos casos grosseira, das condições de campo.

Hanks et al. (1971) e Wierenga \& de Wit (1970) desenvolveram modelos de diferenças finitas, e programas computacionais correspondentes, para solucionar problemas dados pela equação do fluxo linear do calor. Outras abordagens para modelos de diferenças finitas foram apresentadas por Milly (1982), Horton et al. (1984), Anlauf \& Ping (1990) e Moroizumi \& Honiro (2002). Horton \& Chung (1991) apresentam um programa computacional para cálculos numéricos de fluxo de água e calor combinados. Estes modelos têm menos limitações do que os analíticos, pois a equação do fluxo do calor pode ser resolvida para um caso geral, ou seja, para simular uma condição de campo arbitrária, sem necessidade de fazer suposições sobre a difusividade térmica do solo, ou sobre a periodicidade da temperatura na superfície. Observa-se, portanto, que modelos de diferenças finitas são mais flexíveis do que modelos analíticos. A equação diferencial do fluxo de calor é substituída por uma equação de diferenças finitas. Tal substituição é uma aproximação. Entretanto, utilizando passos temporais e espaciais suficientemente pequenos, torna-se uma aproximação razoável.

Validação é um importante tópico em modelagem. Considerando que os modelos numéricos não são exatos, mas aproximados, devem ser testados preliminarmente para erros devido a tal aproximação. Um modo de testar um modelo numérico consiste em comparar seus resultados simulados com os resultados obtidos a partir de um modelo analítico. Isto foi feito por Horton \& Chung (1991), Anlauf \& Ping (1990), Kluitenberg \& Horton (1990), Milly (1982) e Wierenga \& de Wit (1970). Estes testes preliminares não provam que o modelo numérico é correto. $\mathrm{O}$ modelo precisa depois ser testado por meio de comparação com dados experimentais. Estes testes podem somente provar que não há erros grosseiros no modelo, introduzidos pela aproximação das diferenças finitas. Isto tem grande importância, pois se o modelo numérico falhar no teste, é necessário corrigi-lo primeiro, antes de investir tempo e recursos na comparação do modelo numérico com dados experimentais. Assim, modelos analíticos têm também esta importância como ferramenta em testes de modelos numéricos. Cichota et al. (2004) 
indicam como estes testes podem ser feitos de maneira mais exaustiva. Maiores detalhes sobre modelagem numérica de perfil de temperatura do solo encontram-se no Apêndice 2 desta tese.

Willmott (1981) e Zacharias et al. (1996) apresentaram alguns métodos estatísticos para quantificar a adequação de um modelo por meio de comparações de dados simulados com dados experimentais. Embora estes autores estivessem focalizando suas áreas específicas de pesquisa, seus métodos podem ser estendidos para outras áreas, inclusive transferência de calor no solo. Willmott (1981) menciona que "data plots", ou representação gráfica de dados, representam um primeiro, e muito importante, nível de descrição e análise de dados comparativa. Mas menciona também que isto não é suficiente: índices estatísticos devem também ser considerados. Estes autores não mencionam a possibilidade de aplicar seus métodos para comparar um modelo com outro modelo. Entretanto, Cichota et al. (2004) fizeram isto, utilizando estes métodos para comparar um modelo numérico com um modelo analítico. A metodologia desta tese utiliza o método de Willmott (1981) na seção 4.3.3, onde comparam-se dois modelos analíticos para descrever a temperatura do perfil de solo. Além disso, na seção 4.3.4 é desenvolvida uma forma integral para a equação do erro quadrático médio. Esta nova equação foi desenvolvida com base na própria equação usada por Willmott (1981), que fornece o erro quadrático médio por um somatório. 


\section{FUNDAMENTOS TEÓRICOS}

Neste capítulo será apresentada a teoria na qual se baseia a metodologia utilizada no capítulo 4. Esta teoria foi extraída principalmente de Jury et al. (1991) e de de Vries (1963). Para a reprodução deste estudo ou a utilização do método por pesquisadores bastante familiarizados com este assunto, o presente capítulo pode ser desconsiderado, sendo suficiente a leitura a partir do capítulo 4.

\subsection{A equação do fluxo linear de calor no solo}

O transporte de energia no solo ocorre principalmente pelos mecanismos de condução e de convecção de calor latente. Outros processos de transporte existem, como: radiação, convecção de calor pelo fluxo de água líquida, e convecção de calor pelo movimento de ar.

A condução numa substância pura e sólida, considerada em uma direção vertical, é dada pela equação de Fourier:

$$
J_{H c}=-\lambda \frac{d T}{d z}
$$

onde $\mathrm{J}_{\mathrm{Hc}}\left(\mathrm{W} \mathrm{m}^{-2}\right)$ é a densidade de fluxo de calor por condução, $\lambda\left(\mathrm{W} \mathrm{m}^{-1} \mathrm{~K}^{-1}\right)$ é uma constante chamada condutividade térmica da substância, e dT/dz é a taxa de variação da temperatura com a profundidade $\mathrm{z}(\mathrm{m})$. Esta equação descreve o fluxo de calor em um corpo rígido cuja composição permanece constante. 
Em relação à água líquida do solo, a convecção de calor latente refere-se ao transporte de energia de calor latente em vapor de água. Esta energia de calor latente é a energia por massa necessária para a vaporização de água. O transporte de vapor de água de um ponto a outro constitui um transporte de calor latente. Exemplificando: uma certa massa de água líquida é evaporada em um ponto A em um sistema pela adição de calor latente. A seguir, o vapor resultante é movido a um ponto B. No ponto B, o vapor é condensado, retornando a mesma massa de água líquida. Na condensação, calor é liberado. O resultado é que, juntamente com o transporte da massa de água, ocorreu um transporte de calor. A equação da convecção do calor latente, $\mathrm{J}_{\mathrm{HL}}\left(\mathrm{W} \mathrm{m}^{-2}\right)$ é:

$\mathrm{J}_{\mathrm{HL}}=\mathrm{H}_{\mathrm{v}} \mathrm{J}_{\mathrm{v}}$

onde $\mathrm{J}_{\mathrm{v}}\left(\mathrm{kg} \mathrm{m}^{-2} \mathrm{~s}^{-1}\right)$ é o fluxo de massa de vapor de água e $\mathrm{H}_{\mathrm{v}}\left(\mathrm{J} \mathrm{kg}^{-1}\right)$ é o calor latente de vaporização.

O fluxo total de calor no solo, $\mathrm{J}_{\mathrm{H}}\left(\mathrm{W} \mathrm{m}^{-2}\right)$ pode ser escrito adicionando as duas formas principais de transporte:

$J_{H}=-\lambda \frac{d T}{d z}+H_{v} J_{v}$

$O$ valor de $\lambda$ na eq. [14] é dependente da umidade do solo. Quando ocorre o transporte de vapor, ocorre variação na umidade do solo, $\operatorname{logo}$ de $\lambda$. Assim, o valor de $\lambda$ na eq. [14] é o valor instantâneo de condutividade térmica do meio poroso úmido.

Uma aproximação para fluxo de vapor de água em uma dimensão é:

$J_{v}=-D_{T v} \frac{d T}{d z}$ 
onde $\mathrm{D}_{\mathrm{Tv}}\left(\mathrm{kg} \mathrm{m}^{-1} \mathrm{~s}^{-1} \mathrm{~K}^{-1}\right)$ é a difusividade térmica do vapor. Inserindo a eq. [15] na eq. [14], obtém-se:

$J_{H}=-\left(\lambda+H_{v} D_{T v}\right) \frac{d T}{d z}=-\lambda_{e} \frac{d T}{d z}$

onde $\lambda_{\mathrm{e}}\left(\mathrm{W} \mathrm{m}^{-1} \mathrm{~K}^{-1}\right)$ é a condutividade térmica efetiva do meio poroso, que inclui os efeitos combinados de condução e convecção de calor latente.

O processo de transporte de energia térmica no solo obedece ao princípio da conservação de energia. Dado um volume de solo, e havendo um fluxo de energia térmica entrando no solo durante um intervalo de tempo $\Delta \mathrm{t}(\mathrm{s})$, e também um fluxo saindo, o princípio da conservação de energia implica que:

quantidade de energia térmica entrando no volume de solo durante $\Delta \mathrm{t}$

$=$ quantidade de energia térmica saindo do volume de solo durante $\Delta \mathrm{t}+$ aumento no armazenamento de energia térmica do solo durante $\Delta t+$ quantidade de energia térmica desaparecendo no solo durante $\Delta \mathrm{t}$ devido a reações

O último termo da eq. [17] só é necessário se houver alguma fonte ou sorvedouro de energia térmica dentro do solo. Por exemplo, processos químicos ou nucleares podem resultar na transformação de energia química ou nuclear em energia térmica, ou vice versa. No entanto, esses processos têm normalmente um papel muito reduzido no balanço térmico do solo e serão aqui desprezados. Assim, considerando um elemento de volume cúbico de solo, com arestas de valores $\Delta \mathrm{x}, \Delta \mathrm{y}$ e $\Delta \mathrm{z}$, e supondo, por simplicidade, que o fluxo ocorre apenas na direção vertical z, o primeiro termo da eq. [17] pode ser escrito como: 
quantidade de energia térmica entrando no volume de solo durante $\Delta \mathrm{t}$ $=\mathrm{J}_{\mathrm{H}}(\mathrm{x}, \mathrm{y}, \mathrm{z}, \mathrm{t}+1 / 2 \Delta \mathrm{t}) \Delta \mathrm{x} \Delta \mathrm{y} \Delta \mathrm{t}$

onde $\mathrm{J}_{\mathrm{H}}$ é o fluxo de calor no solo avaliado no tempo $\mathrm{t}+1 / 2 \Delta \mathrm{t}$, e o produto $\Delta \mathrm{x} \Delta \mathrm{y}$ é a área transversal do elemento de volume de solo.

Analogamente, o segundo termo da eq. [17] pode ser escrito como:

quantidade de energia térmica saindo do volume de solo durante $\Delta \mathrm{t}$ $=\mathrm{J}_{\mathrm{H}}(\mathrm{x}, \mathrm{y}, \mathrm{z}+\Delta \mathrm{z}, \mathrm{t}+1 / 2 \Delta \mathrm{t}) \Delta \mathrm{x} \Delta \mathrm{y} \Delta \mathrm{t}$

onde $\mathrm{J}_{\mathrm{H}}$ é o fluxo de calor no solo avaliado no tempo $\mathrm{t}+1 / 2 \Delta \mathrm{t}$, e o produto $\Delta \mathrm{x} \Delta \mathrm{y}$ é a área transversal do elemento de volume de solo.

Pode-se chamar de $\mathrm{H}\left(\mathrm{J} \mathrm{m}^{-3}\right)$ ao conteúdo de calor por volume de solo, de forma que o aumento no armazenamento de energia térmica do solo durante $\Delta t$ pode ser escrita como:

aumento no armazenamento de energia térmica do solo durante $\Delta \mathrm{t}$ $=[\mathrm{H}(\mathrm{x}, \mathrm{y}, \mathrm{z}+1 / 2 \Delta \mathrm{z}, \mathrm{t}+\Delta \mathrm{t})-\mathrm{H}(\mathrm{x}, \mathrm{y}, \mathrm{z}+1 / 2 \Delta \mathrm{z}, \mathrm{t})] \Delta \mathrm{x} \Delta \mathrm{y} \Delta \mathrm{z}$

onde $\mathrm{H}$ é considerado no ponto médio do elemento de volume, $z^{+1 / 2} \Delta z$.

Inserindo as eqs. [18], [19] e [20] na equação de balanço de calor, eq. [17], desconsiderando fontes ou sorvedouros, e rearranjando os termos, obtém-se:

$\left[\mathrm{J}_{\mathrm{H}}(\mathrm{x}, \mathrm{y}, \mathrm{z}+\Delta \mathrm{z}, \mathrm{t}+1 / 2 \Delta \mathrm{t})-\mathrm{J}_{\mathrm{H}}(\mathrm{x}, \mathrm{y}, \mathrm{z}, \mathrm{t}+1 / 2 \Delta \mathrm{t})\right] / \Delta \mathrm{z}+$

$[H(x, y, z+1 / 2 \Delta z, t+\Delta t)-H(x, y, z+1 / 2 \Delta z, t)] / \Delta t=0$

Para $\Delta \mathrm{t} \rightarrow 0$ e $\Delta \mathrm{z} \rightarrow 0$, a eq. [21] torna-se a equação diferencial de conservação de calor: 
$\frac{\partial H}{\partial t}+\frac{\partial J_{H}}{\partial z}=0$

O conteúdo de calor por unidade de volume pode ser escrito como:

$\mathrm{H}=\mathrm{C}\left(\mathrm{T}-\mathrm{T}_{\text {ref }}\right)$

onde $\mathrm{C}$ é a capacidade térmica volumétrica do solo, e $\mathrm{T}_{\text {ref }}$ é uma temperatura arbitrária de referência em que $\mathrm{H}=0$. A variável $\mathrm{C}\left(\mathrm{J} \mathrm{m}^{-3} \mathrm{~K}^{-1}\right)$ é definida como a quantidade de calor necessária para elevar uma unidade de volume da substância em $1{ }^{\circ} \mathrm{C}$ de temperatura.

Quando o fluxo de calor, eq. [16], e o conteúdo de calor, eq. [23], são inseridas na equação de conservação de calor, eq. [22], obtém-se, assumindo C constante:

$C \frac{\partial T}{\partial t}=\frac{\partial}{\partial z}\left(\lambda_{e} \frac{\partial T}{\partial z}\right)$

Se a dependência de $\lambda_{\mathrm{e}}$ com z for desprezível, a eq. [24] torna-se:

$\frac{\partial T}{\partial t}=K \frac{\partial^{2} T}{\partial z^{2}}$

onde a difusividade térmica do solo, $\mathrm{K}\left(\mathrm{m}^{2} \mathrm{~s}^{-1}\right)$, é definida como:

$\mathrm{K}=\lambda_{\mathrm{e}} / \mathrm{C}$

Esta ultima equação é a equação do fluxo linear de calor no solo, ou seja, a eq. [1] utilizada na introdução. 


\subsection{Propriedades térmicas do solo}

Conforme mencionado na seção anterior, $K, \lambda_{\mathrm{e}}$ e $\mathrm{C}$ são propriedades térmicas do solo. Devido à dependência entre elas dada pela eq. [25], basta conhecer duas delas para que todas sejam conhecidas.

A capacidade térmica volumétrica, $\mathrm{C}$, pode ser matematicamente expressa como:

$\mathrm{C}=\rho \mathrm{c}$

onde c $\left(\mathrm{J} \mathrm{kg}^{-1} \mathrm{~K}^{-1}\right)$ é o calor especifico e $\rho\left(\mathrm{kg} \mathrm{m}^{-3}\right)$ a densidade. $\mathrm{O}$ valor de $\mathrm{C}$ do solo é determinado pela capacidade térmica volumétrica de seus constituintes:

$\mathrm{C}=\mathrm{x}_{\mathrm{M}} \mathrm{C}_{\mathrm{M}}+\mathrm{x}_{\mathrm{O}} \mathrm{C}_{\mathrm{O}}+\mathrm{x}_{\mathrm{W}} \mathrm{C}_{\mathrm{W}}+\mathrm{x}_{\mathrm{A}} \mathrm{C}_{\mathrm{A}}$

onde o subscrito $\mathrm{M}$ se refere ao material mineral, $\mathrm{W}$ à água, $\mathrm{O}$ à matéria orgânica e $\mathrm{A}$ ao ar. Este último termo pode normalmente ser desprezado. Para a água líquida, uma boa aproximação é $\mathrm{C}_{\mathrm{W}}=4186 \mathrm{~J} \mathrm{~m}^{-3} \mathrm{~K}^{-1}$, sendo o valor exato função da temperatura. A $10^{\circ} \mathrm{C}$, um valor médio para $\mathrm{C}_{\mathrm{M}}$ é $1926 \mathrm{~J} \mathrm{~m}^{-3} \mathrm{~K}^{-1}$, e para $\mathrm{C}_{\mathrm{O}}$ é $2512 \mathrm{~J} \mathrm{~m}^{-3} \mathrm{~K}^{-1}$ (de Vries, 1963). Uma razoável aproximação para a Eq. [27] é, portanto:

$\mathrm{C}=1926 \mathrm{x}_{\mathrm{M}}+2512 \mathrm{x}_{\mathrm{O}}+4186 \mathrm{x}_{\mathrm{W}}$

Eq. [28] é provavelmente a melhor estimativa possível de C, na ausência de maior informação específica sobre um dado solo. Eq. [27] permite estimar C como uma simples função linear das capacidades térmicas e frações volumétricas dos constituintes do solo. A mesma simplicidade não se aplica ao cálculo de $\lambda$, como será visto a seguir. A eq. [28] mostra que a umidade do solo influencia consideravelmente o valor de C. Como um cálculo aproximado, supõe-se um solo com $50 \%$ de porosidade total, logo $\mathrm{x}_{\mathrm{M}}=0,5$, e com $\mathrm{x}_{\mathrm{O}} \sim 0$, de forma que a eq. [28] torna-se uma função linear de $\mathrm{x}_{\mathrm{W}}$ :

$\mathrm{C}=963+4186 \mathrm{x}_{\mathrm{W}}$ 
Assim, para o solo seco, $\mathrm{x}_{\mathrm{W}} \sim 0$, tem-se $\mathrm{C}=963 \mathrm{~J} \mathrm{~m}^{-3} \mathrm{~K}^{-1}$, e para o solo saturado, $\mathrm{x}_{\mathrm{W}}=0,5$, tem-se $\mathrm{C}=3056 \mathrm{~J} \mathrm{~m}^{-3} \mathrm{~K}^{-1}$. Ou seja, o valor máximo de C é aproximadamente o triplo do mínimo, o que representa uma variação considerável de $\mathrm{C}$ com a umidade. Como valor típico de $\mathrm{C}$ para o solo em condições de campo a teores intermediários de água pode-se considerar $\mathrm{C}=2000 \mathrm{~J} \mathrm{~m}^{-3} \mathrm{~K}^{-1}$.

A estimativa da condutividade térmica em função da composição do solo é mais complexa porque, além de depender de $\mathrm{x}_{\mathrm{M}}, \mathrm{x}_{\mathrm{O}}, \mathrm{x}_{\mathrm{W}}$ e $\mathrm{x}_{\mathrm{A}}$, depende também do tamanho e do arranjo das partículas de solo, e do contato interfacial entre as fases líquida e sólida. Devido à sua estrutura cristalina altamente organizada, diversos minerais apresentam anisotropia quanto às suas condutividades térmicas; assim, a condutividade do quartzo é de $11,0 \mathrm{~W} \mathrm{~m}^{-1} \mathrm{~K}^{-1}$ quando medido paralelamente ao eixo do cristal, e $6,7 \mathrm{~W} \mathrm{~m}^{-1} \mathrm{~K}^{-1}$ quando medido perpendicularmente ao eixo. Esta é uma diferença considerável, o que exemplifica a influência do arranjo de partículas. Outro fato notável é a enorme diferença entre os valores de $\lambda$ entre os minerais, água e ar. Para a água, $\lambda=0,6$ $\mathrm{W} \mathrm{m}^{-1} \mathrm{~K}^{-1}$, e para o ar, $\lambda=0,025 \mathrm{~W} \mathrm{~m}^{-1} \mathrm{~K}^{-1}$. Fazendo um cálculo aproximado com os valores acima, encontra-se que a razão entre os valores de $\lambda$ para quartzo, água e ar é, aproximadamente, 356:24:1. Cada valor difere do seguinte em uma ordem de grandeza. Neste cálculo, considerou-se, no caso do quartzo, um valor médio de $\lambda=8,9 \mathrm{~W} \mathrm{~m}^{-1} \mathrm{~K}^{-1}$. Devido a esta grande diferença, $\lambda$ aumenta muito com a entrada de água no solo, substituindo o ar. Além disso, Nakshabandi et al. (1965) relacionaram o estado energético da água no solo com sua condutividade térmica; este estado, por sua vez, relaciona-se com o contato interfacial entre as fases líquida e sólida. As medidas experimentais de $\lambda$ são ainda afetadas pela convecção, mencionada na seção anterior, de modo que, na prática, somente é possível medir $\lambda_{\mathrm{e}}$. Em uma situação típica, o valor de $\lambda_{\text {e }}$ pode ser multiplicado por oito a dez, quando um solo seco torna-se saturado com $\mathrm{X}_{\mathrm{W}}=0,5$ (Van Duin, 1963, citado $^{1}$ por Jury et al., 1991, p. 181)

\footnotetext{
1 Van Duin, R.H.A. The influence of soil management on the temperature wave near the surface. Technical Bulletin 29. Institute for Land and Water Management Research, Wageningen. 1963
} 
Conforme foi visto no capítulo 1, os modelos analíticos estudados nesta tese consideram $\mathrm{K}$ = constante. Dada a dependência entre as propriedades térmicas do solo e sua umidade, acima mencionada, torna-se necessário enfatizar que tais modelos analíticos, apesar de apresentarem as vantagens indicadas, são apenas uma aproximação, cujas limitações devem ser reconhecidas por quem os utilize.

\subsection{Aplicação da equação do fluxo linear de calor no solo}

Conforme mencionado no capítulo 1 , tem sido verificado experimentalmente que a temperatura superficial do solo ajusta-se a uma equação senoidal, conforme a eq. [2]. Considerando que a fonte de calor na superfície é periódica, é também razoável supor que, muito abaixo da superfície, a temperatura permanecerá igual à temperatura média, conforme a eq. [3]. Sabe-se, ainda, que o transporte de calor é regido pela equação do fluxo linear de calor, eq. [1]. Assim, pode-se aplicar a eq. [1] para este problema. Ou seja, deve-se resolver a equação diferencial do fluxo linear de calor no solo, eq. [1], satisfazendo as condições de contorno dadas pelas eq. [2] e [3]. Com isto, encontrar-se-á a função $\mathrm{T}(\mathrm{z}, \mathrm{t})$, que fornece a temperatura de todo o perfil do solo. Em outras palavras, uma aplicação da equação do fluxo linear de calor é determinar a temperatura do perfil do solo a partir de informações sobre a temperatura na superfície, o que é notável. A seguir, será apresentada a solução do problema pelo método de separação de variáveis. Esta solução é apresentada por Carslaw \& Jaeger (1959) e por Van Wijk \& de Vries (1963). Entretanto, Kirkham \& Powers (1972, p. 468-473) apresentam-na de maneira mais didática. A apresentação a seguir está ainda mais clara do que a de Kirkham \& Powers (1972, p. 468-473). Maiores considerações sobre a teoria das equações diferenciais parciais, com ênfase em suas aplicações na física do solo, encontram-se em Prevedello (1996). Para a teoria das equações diferenciais elementares em geral, um conhecido livro-texto é Boyce \& Diprima (1965).

Uma forma de resolver equações diferenciais é por tentativas. Tenta-se imaginar uma solução, e, por substituição na equação diferencial, verifica-se se é correta ou não. No caso do problema dado pelas eq. [1], [2] e [3], é difícil imaginar uma solução. 
Dificilmente alguém conseguiria imaginar a solução, eq. [4], por meras tentativas, sem usar nenhum método para solucionar equações diferenciais. Um dos métodos existentes chama-se "método de separação de variáveis". Este método envolve, na verdade, tentativas, mas um tipo de tentativa mais específica, mais direcionada.

Antes de prosseguir, para simplificar o problema, será considerado $\mathrm{T}_{\mathrm{a}}=0$ e $\varphi=0$, de modo que as eq. [2] e [3] tornam-se

$$
\begin{aligned}
& T(0, t)=A \sin (\omega t) \\
& \lim _{z \rightarrow \infty} T(z, t)=0
\end{aligned}
$$

Pelo método de separação de variáveis, supõe-se que a solução é do tipo:

$$
T(z, t)=f(z) g(t)
$$

Tal suposição é apenas uma tentativa, ou seja, uma hipótese a ser testada. Não há qualquer motivo, em princípio, para que a solução seja separável. Levanta-se esta hipótese, e verificam-se as conseqüências da mesma. Chegando a uma solução, então se diz que o método funcionou. Mas nada garante que não se chega a um absurdo, ao invés de uma solução, o que poderia acontecer, caso a solução não fosse uma equação separável. Assim, é necessário verificar as conseqüências lógicas da suposição acima, dada pela eq. [32]. Substituindo a eq. [32] na eq. [1], obtém-se:

$\mathrm{g}^{\prime}(\mathrm{t}) /[\mathrm{Kg}(\mathrm{t})]=\mathrm{f}^{\prime \prime}(\mathrm{z}) / \mathrm{f}(\mathrm{z})$

Se for suposto que o lado esquerdo da eq. [33] varie com $t$, e considerando que o lado direito não varia com t, então chegar-se-ia a um absurdo, ou seja, de que diferentes números são iguais a um mesmo número. Isto logicamente implica que o lado esquerdo não varia com t, ou seja, que é constante. Por conseguinte, o lado direito é igual a esta 
mesma constante, a qual será chamada de r. Desta forma, a eq. [33] leva a duas equações diferenciais lineares ordinárias:

$\mathrm{g}^{\prime}(\mathrm{t})-\mathrm{rKg}(\mathrm{t})=0$

$\mathrm{f} ”(\mathrm{z})-\mathrm{rf}(\mathrm{z})=0$

cujas soluções são, respectivamente:

$\mathrm{g}(\mathrm{t})=\mathrm{G} \exp (\mathrm{r} \mathrm{K} \mathrm{t})$

$f(z)=F \exp \left( \pm r^{1 / 2} z\right)$

sendo F e G constantes arbitrárias. Levando as eq. [36] e [37] na eq. [32] obtém-se:

$\mathrm{T}(\mathrm{z}, \mathrm{t})=\mathrm{B} \exp \left( \pm \mathrm{zr}^{1 / 2}\right) \exp (\mathrm{r} \mathrm{K} \mathrm{t})$

$\mathrm{ou}$

$\mathrm{T}(\mathrm{z}, \mathrm{t})=\mathrm{B} \exp \left(\mathrm{rKt} \pm \mathrm{zr}^{1 / 2}\right)$

com $B=F G$. Observa-se que a eq. [39] obviamente não satisfaz as condições de contorno, eq. [30] e [31]. Assim, é necessário recorrer a um artifício. Ao invés de resolver o problema original, dado pelas eq. [1], [30] e [31], um outro problema será resolvido, dado pelas eq. [40], [41] e [42]:

$$
\begin{aligned}
& \frac{\partial T^{*}}{\partial t}=K \frac{\partial^{2} T^{*}}{\partial z^{2}} \\
& T^{*}(0, \mathrm{t})=\mathrm{A} \cos (\omega \mathrm{t})+\mathrm{i} A \sin (\omega \mathrm{t}) \\
& \lim _{z \rightarrow \infty} T^{*}(z, t)=0
\end{aligned}
$$


sendo

$T^{*}(z, t)=f(z, t)+i T(z, t)$

onde $\mathrm{T}^{*}$ é uma variável dependente complexa, função de duas variáveis independentes reais, $\mathrm{z}$ e t; e i é a unidade imaginária, $i=\sqrt{-1}$. A parte imaginária de $\mathrm{T}^{*}, \mathrm{~T}(\mathrm{z}, \mathrm{t})$, representa a temperatura de interesse; ou seja, a temperatura que se mede no mundo físico, a qual é um numero real. A parte real, $\mathrm{f}(\mathrm{z}, \mathrm{t})$, é apenas um artifício para resolver o problema, sem significado físico.

Reiniciando o procedimento de separação de variáveis, desta vez trabalhando com $T^{*}$ ao invés de $T$, chega-se a uma equação análoga a eq. [39]:

$\mathrm{T}^{*}(\mathrm{z}, \mathrm{t})=\mathrm{B} \exp \left(\mathrm{rKt} \pm \mathrm{z} \mathrm{r}^{1 / 2}\right)$

Continuando o procedimento como no caso anterior, mas desta vez trabalhando com variáveis complexas, deve-se verificar se a eq. [43] satisfaz ou não as condições de contorno dadas pelas eq. [41] e [42]. A primeira verificação será feita com respeito à eq. [41], que pode ser escrita como:

$\mathrm{T}^{*}(0, \mathrm{t})=\mathrm{A} \exp (\mathrm{i} \omega \mathrm{t})$

A eq. [43] implica que:

$\mathrm{T}^{*}(0, \mathrm{t})=\mathrm{B} \exp (\mathrm{r} \mathrm{K} \mathrm{t})$

As constantes $r$ e B devem ser tais que os lados direitos das eq. [44] e [45] sejam iguais, o que exige que $A=B$ e que $r=i \omega / K$. Com estes valores de $B$ e $r$, a eq. [43] torna-se:

$\mathrm{T}^{*}(\mathrm{z}, \mathrm{t})=\mathrm{A} \exp \left[\mathrm{i} \omega \mathrm{t} \pm \mathrm{z}(\mathrm{i} \omega / \mathrm{K})^{1 / 2}\right]$ 
Assim, a condição de contorno dada pela eq. [41] não leva a uma incoerência como no procedimento anterior (trabalhando com variáveis reais), mas leva apenas a exigências razoáveis sobre os valores de r e B. Deve-se agora verificar se a eq. [43] satisfaz ou não a condição de contorno dada pela eq. [42]. Como a eq. [43] assume, obrigatoriamente, a forma dada pela eq. [46], deve-se então verificar se a eq. [46] satisfaz tal condição de contorno. Para isto, é conveniente reescrever a eq. [46] de outra forma, dada pelas eq. [51] e [52] abaixo, obtidas através do procedimento que segue. Inicialmente, é imediato que a eq. [46] pode ser escrita como:

$\mathrm{T}^{*}(\mathrm{z}, \mathrm{t})=\mathrm{A} \exp \left[\mathrm{i} \omega \mathrm{t} \pm \mathrm{zi} i^{1 / 2}(\omega / \mathrm{K})^{1 / 2}\right]$

A seguir, observe-se que o termo $\mathrm{i}^{1 / 2}$, que aparece na eq. [47], pode ser escrito como:

$\mathrm{i}^{1 / 2}=(\mathrm{i}+1) / 2^{1 / 2}$

Demonstração da eq. [48]:

$$
\begin{aligned}
& i=\exp (i \pi / 2)=\cos (\pi / 2)+i \sin (\pi / 2), \log 0 \\
& i^{1 / 2}=[\exp (i \pi / 2)]^{1 / 2}=\exp (i \pi / 4)=\cos (\pi / 4)+i \sin (\pi / 4) \\
& \text { Como } \cos (\pi / 4)=\sin (\pi / 4)=1 / 2^{1 / 2}, \text { então: } \\
& i^{1 / 2}=1 / 2^{1 / 2}+i 1 / 2^{1 / 2}=(i+1) / 2^{1 / 2}
\end{aligned}
$$

Utilizando a eq. [48], a eq. [47] pode ser escrita como:

$T^{*}(\mathrm{z}, \mathrm{t})=\mathrm{A} \exp \left[\mathrm{i} \omega \mathrm{t} \pm \mathrm{z}(\mathrm{i}+1)(\omega / \mathrm{K})^{1 / 2} / 2^{1 / 2}\right]$

ou como: 
$\mathrm{T}^{*}(\mathrm{z}, \mathrm{t})=\mathrm{A} \exp \left\{\mathrm{i} \omega \mathrm{t} \pm \mathrm{z}(\mathrm{i}+1)[\omega /(2 \mathrm{~K})]^{1 / 2}\right\}$

Considerando a eq. [5], a eq. [49] torna-se:

$T^{*}(z, t)=A \exp \left[i \omega t \pm z(i+1) D^{-1}\right]$

A eq. [50] pode ser desmembrada em duas:

$\mathrm{T}^{*}(\mathrm{z}, \mathrm{t})=\mathrm{A} \exp \left[\mathrm{i} \omega \mathrm{t}+\mathrm{z}(\mathrm{i}+1) \mathrm{D}^{-1}\right]$

$\mathrm{T}^{*}(\mathrm{z}, \mathrm{t})=\mathrm{A} \exp \left[\mathrm{i} \omega \mathrm{t}-\mathrm{z}(\mathrm{i}+1) \mathrm{D}^{-1}\right]$

Deve-se aqui recordar que as eq. [51] e [52] representam a própria eq. [46] sob outra forma, após uma manipulação algébrica. Assim, ao invés de verificar se a eq. [46] satisfaz ou não a condição de contorno dada pela eq. [42], verificar-se-á se a eq. [51] ou a eq. [52] satisfaz tal condição. É desejável que pelo menos uma delas satisfaça; do contrário, o método da separação usando variáveis complexas teria falhado, e seria necessário outro método para resolver o problema em questão. Não implicaria que o problema é insolúvel, mas implicaria que a solução não é separável. Para testar esta última condição de contorno, é conveniente escrever as eq. [51] e [52] como as eq. [53] e [54] abaixo:

$$
\begin{aligned}
& \mathrm{T}^{*}(\mathrm{z}, \mathrm{t})=A \exp \left[\mathrm{i} \omega \mathrm{t}+(\mathrm{zi}+\mathrm{z}) \mathrm{D}^{-1}\right] \Rightarrow \mathrm{T}^{*}(\mathrm{z}, \mathrm{t})=\mathrm{A} \exp \left(\mathrm{i} \omega \mathrm{t}+\mathrm{i} \mathrm{zD}^{-1}+\mathrm{zD}^{-1}\right) \Rightarrow \\
& \mathrm{T}^{*}(\mathrm{z}, \mathrm{t})=\mathrm{A} \exp \left(\mathrm{i} \omega \mathrm{t}+\mathrm{i} \mathrm{zD}^{-1}\right) \exp \left(\mathrm{zD}^{-1}\right) \Rightarrow \\
& \mathrm{T}^{*}(\mathrm{z}, \mathrm{t})=\mathrm{A} \exp \left[\mathrm{i}\left(\omega \mathrm{t}+\mathrm{zD}^{-1}\right)\right] \exp \left(\mathrm{zD}^{-1}\right) \Rightarrow \\
& \mathrm{T}^{*}(\mathrm{z}, \mathrm{t})=\mathrm{A} \exp \left(\mathrm{zD}^{-1}\right) \cos \left(\omega \mathrm{t}+\mathrm{zD}^{-1}\right)+\mathrm{i} \exp \left(\mathrm{zD}^{-1}\right) \sin \left(\omega \mathrm{t}+\mathrm{zD}^{-1}\right) \\
& \mathrm{T}^{*}(\mathrm{z}, \mathrm{t})=\mathrm{A} \exp \left[\mathrm{i} \omega \mathrm{t}-(\mathrm{zi}+\mathrm{z}) \mathrm{D}^{-1}\right] \Rightarrow \mathrm{T}^{*}(\mathrm{z}, \mathrm{t})=\mathrm{A} \exp \left(\mathrm{i} \omega \mathrm{t}-\mathrm{i} \mathrm{zD}^{-1}-\mathrm{zD}^{-1}\right) \Rightarrow \\
& \mathrm{T}^{*}(\mathrm{z}, \mathrm{t})=\mathrm{A} \exp \left(\mathrm{i} \omega \mathrm{t}-\mathrm{i} \mathrm{D}^{-1}\right) \exp \left(-\mathrm{zD}^{-1}\right) \Rightarrow \\
& \mathrm{T}^{*}(\mathrm{z}, \mathrm{t})=\mathrm{A} \exp \left[\mathrm{i}\left(\omega \mathrm{t}-\mathrm{zD}^{-1}\right)\right] \exp \left(-\mathrm{zD}^{-1}\right) \Rightarrow
\end{aligned}
$$


$T^{*}(z, t)=A \exp \left(-z D^{-1}\right) \cos \left(\omega t-z D^{-1}\right)+i A \exp \left(-z D^{-1}\right) \sin \left(\omega t-z^{-1}\right)$

A condição de contorno dada pela eq. [42] exige que, para $z$ tendendo a infinito, tanto a parte real como a imaginária de $\mathrm{T}^{*}$ tendam a zero. No caso da eq. [53] , quando $\mathrm{z}$ tende a infinito, o fator exp $\left(\mathrm{z} \mathrm{D}^{-1}\right)$ também tende a infinito, enquanto o fator $\sin \left(\omega t+z D^{-1}\right)$ oscila entre +1 e -1 . Logo o produto de ambos os fatores oscila entre $+\infty$ e $-\infty$. Assim, nem a parte real nem a parte imaginária tendem a zero. Portanto, a eq. [53] deve ser rejeitada por não satisfazer esta condição de contorno. No caso da eq. [54], quando $\mathrm{z}$ tende a infinito, o fator $\exp \left(-\mathrm{z}^{-1}\right)$ tende a zero, enquanto o fator $\sin \left(\omega t+z D^{-1}\right)$ oscila entre +1 e -1 . Logo o produto de ambos os fatores tende a zero. Dessa forma, tanto a parte real como a parte imaginária tendem a zero. Assim, aceita-se a eq. [54], e fica solucionado o problema dado pelas eq. [40], [41] e [42]. Observa-se que, coincidentemente, a função $T^{*}(z, t)$ era de fato separável, de modo que o método da separação de variáveis foi frutífero. A solução de interesse, $\mathrm{T}(\mathrm{z}, \mathrm{t})$, é a parte imaginária de $T^{*}(z, t)$, ou seja:

$\mathrm{T}(\mathrm{z}, \mathrm{t})=\mathrm{A} \exp (-\mathrm{z} / \mathrm{D}) \sin (\omega \mathrm{t}-\mathrm{z} / \mathrm{D})$

Observa-se que, obviamente, uma constante também é solução da eq. [1]. Ou seja, $\mathrm{T}(\mathrm{z}, \mathrm{t})=\mathrm{T}_{\mathrm{a}}$ é solução, para qualquer valor de $\mathrm{T}_{\mathrm{a}}$. Basta substituir $\mathrm{T}(\mathrm{z}, \mathrm{t})=\mathrm{T}_{\mathrm{a}}$ na eq. [1] para verificar que isto é verdade. Além disso, a soma de duas soluções é uma solução como será demonstrado no parágrafo seguinte. Logo, a solução para este problema com $\mathrm{T}_{\mathrm{a}}$ diferente de zero é simplesmente:

$\mathrm{T}(\mathrm{z}, \mathrm{t})=\mathrm{T}_{\mathrm{a}}+\mathrm{A} \exp (-\mathrm{z} / \mathrm{D}) \sin (\omega \mathrm{t}-\mathrm{z} / \mathrm{D})$

A demonstração de que a soma de duas soluções é também uma solução é a seguinte. Suponhamos que $T_{1}, T_{2}, T_{3}, \ldots T_{n}$ sejam funções de $z$ e $t$ que satisfazem a 
eq. [1]. Deseja-se demonstrar que a eq. [1] é necessariamente satisfeita por uma função $\mathrm{T}_{\mathrm{S}}$, dada pela soma destas outras funções:

$\mathrm{T}_{\mathrm{S}}(\mathrm{z}, \mathrm{t})=\mathrm{T}_{1}(\mathrm{z}, \mathrm{t})+\mathrm{T}_{2}(\mathrm{z}, \mathrm{t})+\ldots+\mathrm{T}_{\mathrm{n}}(\mathrm{z}, \mathrm{t})$

Como, por hipótese, as funções $T_{i}, I=1,2, . . n$, satisfazem à eq. [1], então:

$$
\begin{aligned}
& \frac{\partial T_{1}}{\partial t}=K \frac{\partial^{2} T_{1}}{\partial z^{2}} \\
& \frac{\partial T_{2}}{\partial t}=K \frac{\partial^{2} T_{2}}{\partial z^{2}} \\
& : \\
& \frac{\partial T_{n}}{\partial t}=K \frac{\partial^{2} T_{n}}{\partial z^{2}}
\end{aligned}
$$

Somando estas equações, conclui-se que a seguinte equação é necessariamente verdadeira:

$$
\frac{\partial T_{1}}{\partial t}+\frac{\partial T_{2}}{\partial t}+\ldots+\frac{\partial T_{n}}{\partial t}=K \frac{\partial^{2} T_{1}}{\partial z^{2}}+K \frac{\partial^{2} T_{2}}{\partial z^{2}}+\ldots+K \frac{\partial^{2} T_{n}}{\partial z^{2}}
$$

Neste ponto, será feito uso de um conhecido teorema do cálculo: "a derivada de uma soma é igual a soma das derivadas das parcelas" (p.e. Guidorizzi, 1995, p. 172). Considerando este teorema, a eq. [57] implica necessariamente que:

$$
\frac{\partial\left(T_{1}+T_{2}+\ldots+T_{n}\right)}{\partial t}=K \frac{\partial^{2}\left(T_{1}+T_{2}+\ldots+T_{n}\right)}{\partial z^{2}}
$$

Pela eq. [56], a eq. [58] torna-se: 


$$
\frac{\partial\left(T_{S}\right)}{\partial t}=K \frac{\partial^{2}\left(T_{S}\right)}{\partial z^{2}}
$$

como se desejava demonstrar.

Finalmente, para a constante de fase diferente de zero, o método a ser imediatamente utilizado é por tentativas, e logo observa-se, por substituição, que a eq. [4] satisfaz as eq. [1], [2] e [3].

Uma inspeção da eq. [4] revela várias propriedades desta solução (Jury et al., 1991):

(i) A temperatura, em qualquer profundidade $z$, é uma onda senoidal com amplitude $\mathrm{A}(\mathrm{z})$ dada por:

$\mathrm{A}(\mathrm{z})=\mathrm{A}(0) \exp (-\mathrm{z} / \mathrm{D})$

(ii) a fase da onda é retardada com relação a superfície por um tempo z / (D $\omega$ ).

Por exemplo, na superfície, em $\mathrm{t}=0$, o argumento vale $\varphi$. Em uma profundidade $\mathrm{z}, \mathrm{o}$ argumento não valerá $\varphi$ para $\mathrm{t}=0$, mas para $\mathrm{t}$ satisfazendo a equação:

$\omega \mathrm{t}-\mathrm{z} / \mathrm{D}=0 \Rightarrow \mathrm{t}=\mathrm{z} /(\mathrm{D} \omega)$

Ou seja, o mesmo argumento somente será atingido em um tempo t posterior a zero. Este tempo t é diretamente proporcional a profundidade. Quanto maior a profundidade, maior será o atraso.

(iii) todas as profundidades têm o mesmo período, $\tau=2 \pi / \omega$;

(iv) todas as profundidades têm a mesma temperatura média anual, $\mathrm{T}_{\mathrm{a}}$. 
O valor de D tem um significado físico importante: D caracteriza a penetração de uma onda de temperatura. A uma profundidade $\mathrm{z}=\mathrm{D}$, ter-se-á uma onda com amplitude $\mathrm{A}(\mathrm{D})=\mathrm{e}^{-1} \mathrm{~A}(0) \cong 0,37 \mathrm{~A}(0)$. Para uma profundidade de $\mathrm{z}=\mathrm{n} \mathrm{D}$, ter-se-á uma amplitude $\mathrm{A}(\mathrm{nD})=\mathrm{e}^{-\mathrm{n}} \mathrm{A}(0) \cong(0,37)^{\mathrm{n}} \mathrm{A}(0)$. Para $\mathrm{z}=5 \mathrm{D}$, a amplitude em $\mathrm{z}$ reduz-se a menos de $1 \%$ da amplitude na superfície.

Tomando como base um valor modal da capacidade calórica volumétrica $\left(\mathrm{C}=2000 \mathrm{~J} \mathrm{~m}^{-3} \mathrm{~K}^{-1}\right.$, conforme seção 3.2) e um valor típico de condutividade térmica de

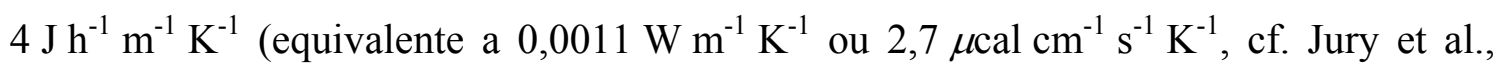
1991, p.183), encontra-se $K=4$ / $2000=0,002 \mathrm{~m}^{2} \mathrm{~h}^{-1}$ que equivale, em unidades do SI, a $\mathrm{K}=5,56 \times 10^{-7} \mathrm{~m}^{2} \mathrm{~s}^{-1}$ e que pode ser, portanto, considerado um valor modal para $\mathrm{K}$. Para ondas com o período de um dia, $\omega_{\mathrm{d}}=2 \pi /(86.400 \mathrm{~s})=7,2710^{-5} \mathrm{rad} \mathrm{s}^{-1}$, o que resulta em $\mathrm{D}_{\mathrm{d}}=0,124 \mathrm{~m}$, aplicando a eq. [5]. Para período anual, tem-se $\omega_{\mathrm{y}}=2 \pi / 31536000=1,9910^{-7} \mathrm{rad} \mathrm{s}^{-1}, \mathrm{D}_{\mathrm{y}}=2,36 \mathrm{~m}$. Assim, a onda de período diário estará reduzida a menos de $1 \%$ à cerca de $0,60 \mathrm{~m}$ de profundidade, e a onda de período anual, a cerca de $12 \mathrm{~m}$. Este efeito pode ser resumido no seguinte princípio: uma onda de temperatura de alta freqüência tem menor penetração no solo do que uma onda de baixa freqüência. 


\section{MATERIAL E MÉTODOS}

\subsection{Dados de temperatura}

A fim de comparar predições do modelo analítico corrigido, a ser apresentado na seção seguinte, eq. [66], com o modelo analítico tradicional, eq. [10], são necessários valores experimentais de certos parâmetros que compõem estas equações. Para estas comparações, foi suficiente usar um valor típico de difusividade térmica do solo, $\mathrm{K}=5,56 \times 10^{-7} \mathrm{~m}^{2} \mathrm{~s}^{-1}$, conforme seção 3.3. Outros parâmetros vistos na seção 3.3 são: $\omega_{\mathrm{y}}=1,9910^{-7} \mathrm{rad} \mathrm{s}^{-1}, \omega_{\mathrm{d}}=7,2710^{-5} \mathrm{rad} \mathrm{s}^{-1}, \mathrm{D}_{\mathrm{d}}=0,124 \mathrm{~m}, \mathrm{D}_{\mathrm{y}}=2,36 \mathrm{~m}$. Alguns dos parâmetros necessários foram obtidos de Elias et al. (2004), referentes a temperatura do solo em São Paulo, SP, Brasil: $\mathrm{A}_{\mathrm{y}}=3,51{ }^{\circ} \mathrm{C}, \mathrm{A}_{\mathrm{d}}=7,49{ }^{\circ} \mathrm{C}, \mathrm{B}=0,95{ }^{\circ} \mathrm{C}, \omega_{\mathrm{b}}=\omega_{\mathrm{y}}$,

$\varphi_{\mathrm{d}}=1,85 \mathrm{rad}, \beta=1,73 \mathrm{rad}$. Maiores detalhes sobre a origem dos dados de Elias et al. (2004) encontram-se no Apêndice 1. Também se utilizaram valores de $\omega_{\mathrm{b}}$ de outras duas localidades estudadas por Elias et al. (2004), Sydney, Austrália, e Ribeirão Preto, SP, Brasil, cujos valores são $\omega_{\mathrm{b}}=2 \omega_{\mathrm{y}}$ e $\omega_{\mathrm{b}}=\omega_{\mathrm{y}}$, respectivamente. Estes dois últimos valores foram somente usados como exemplos no final da seção 4.3.4; não foram usados como parâmetros de entrada nas comparações entre as eq. [10] e [66].

\subsection{Modelo analítico para temperatura do perfil do solo}

A modelagem analítica do perfil de temperatura do solo será aqui aperfeiçoada, fazendo uma correção na condição de contorno da superfície, dada pela eq. [9], substituindo a constante $A_{d}$ pela variável $C(t)$. A variável $C(t)$ é dada pela eq. [11]. Com esta correção, a eq. [9] torna-se: 
$T(0, t)=T_{a y}+A_{y} \sin \left(\omega_{y} t+\varphi_{y}\right)+\left[A_{d}+B \sin \left(\omega_{b} t+\beta\right)\right] \sin \left(\omega_{d} t+\varphi_{d}\right)$

ou

$T(0, t)=T_{a y}+A_{y} \sin \left(\omega_{y} t+\varphi_{y}\right)+A_{d} \sin \left(\omega_{d} t+\varphi_{d}\right)+B \sin \left(\omega_{d} t+\varphi_{d}\right) \sin \left(\omega_{b} t+\beta\right)$

A fim de obter-se uma solução da eq. [1] para a nova condição de contorno dada pela eq. [61], deve-se notar, uma vez mais, que uma combinação linear de soluções independentes da eq. [1] é também uma solução da eq. [1]. No entanto, o termo adicional na eq. [61] envolve um produto, não uma soma, de senóides. Mas este produto pode ser facilmente transformado em uma soma usando as identidades trigonométricas (p.e. Abramowitz \& Stegun, 1972, p. 72-73):

$\sin a \sin b=[\cos (a-b)-\cos (a+b)] / 2$

$\cos a=\sin (a+\pi / 2)$

Combinando eq. [62] e [63] resulta em:

$\sin a \sin b=[\sin (a-b+\pi / 2)-\sin (a+b+\pi / 2)] / 2$

A partir da eq. [64], observa-se que a eq. [61] pode ser escrita como:

$\mathrm{T}(0, \mathrm{t})=\mathrm{T}_{\mathrm{ay}}+\mathrm{A}_{\mathrm{y}} \sin \left(\omega_{\mathrm{y}} \mathrm{t}+\varphi_{\mathrm{y}}\right)+\mathrm{A}_{\mathrm{d}} \sin \left(\omega_{\mathrm{d}} \mathrm{t}+\varphi_{\mathrm{d}}\right)+$

$(B / 2) \sin \left[t\left(\omega_{d}-\omega_{b}\right)+\left(\varphi_{d}-\beta\right)+\pi / 2\right]-(B / 2) \sin \left[t\left(\omega_{d}+\omega_{b}\right)+\left(\varphi_{d}+\beta\right)+\pi / 2\right]$

Então a solução das eq. [1], [3] e [65] torna-se:

$\mathrm{T}(\mathrm{z}, \mathrm{t})=\mathrm{T}_{\mathrm{ay}}+\mathrm{A}_{\mathrm{y}} \exp \left(-\mathrm{z} / \mathrm{D}_{\mathrm{y}}\right) \sin \left(\omega_{\mathrm{y}} \mathrm{t}-\mathrm{z} / \mathrm{D}_{\mathrm{y}}+\varphi_{\mathrm{y}}\right)+$

$$
A_{d} \exp \left(-z / D_{d}\right) \sin \left(\omega_{d} t-z / D_{d}+\varphi_{d}\right)+
$$




$$
\begin{aligned}
& (\mathrm{B} / 2) \exp \left(-\mathrm{z} / \mathrm{D}^{\prime}\right) \sin \left(\omega^{\prime} \mathrm{t}-\mathrm{z} / \mathrm{D}^{\prime}+\left(\varphi_{\mathrm{d}}-\beta\right)+\pi / 2\right)- \\
& (\mathrm{B} / 2) \exp \left(-\mathrm{z} / \mathrm{D}^{\prime}\right) \sin \left(\omega^{\prime} \mathrm{t}-\mathrm{z} / \mathrm{D}^{\prime}+\left(\varphi_{\mathrm{d}}+\beta\right)+\pi / 2\right)
\end{aligned}
$$

onde

$$
\begin{aligned}
& \omega^{\prime}=\left(\omega_{\mathrm{d}}-\omega_{\mathrm{b}}\right) \\
& \omega^{\prime \prime}=\left(\omega_{\mathrm{d}}+\omega_{\mathrm{b}}\right) \\
& D^{\prime}=\sqrt{\frac{2 K}{\omega^{\prime}}} \\
& D^{\prime \prime}=\sqrt{\frac{2 K}{\omega^{\prime \prime}}}
\end{aligned}
$$

As variáveis D' e D" são simplesmente as profundidades de amortecimento, dadas pela eq. [5], para os dois termos exponencial-senoidais adicionais.

De acordo com a eq. [11], é imediato que, para $\mathrm{B}=0$, a amplitude diária é constante. A eq. [66] aplica-se a qualquer valor de $\mathrm{B}$, inclusive $\mathrm{B}=0$, ou a amplitude diária constante. Por outro lado, se a amplitude diária é constante, a função $\mathrm{T}(\mathrm{z}, \mathrm{t})$ deve ser dada pela eq. [10]. Assim, o caso particular em que $B=0$ pode ser descrito por ambas as equações, [10] e [66]. Logo, estas equações devem ser iguais para $\mathrm{B}=0$. Fazendo $\mathrm{B}=0$ na eq. [66], observa-se que esta de fato reduz-se à eq. [10], o que é um sinal de consistência da teoria aqui desenvolvida.

\subsection{Comparação dos modelos analíticos}

\subsubsection{Profundidades de amortecimento}

Uma comparação preliminar de predições das eq. [10] e [66] foi feita considerando as profundidades de amortecimento que aparecem nestas equações: $D_{y}, D_{d}, D^{\prime}$ e D’. 


\subsubsection{Profundidade de penetração}

Embora o valor de D caracterize a penetração de uma onda de temperatura, será aqui desenvolvido um outro conceito, bastante simples, que também seria útil para caracterizar a penetração. Será aqui definida a "profundidade de penetração" como uma profundidade $\mathrm{z}_{\mathrm{m}}$ suficientemente grande, tal que a variação de temperatura seja muito pequena; por exemplo, $0,1{ }^{\circ} \mathrm{C}$ ou $0,01{ }^{\circ} \mathrm{C}$. De acordo com a eq. [4] , a temperatura $\mathrm{T}$ a uma certa profundidade $\mathrm{z}_{\mathrm{M}}$, em um tempo t, é:

$\mathrm{T}\left(\mathrm{z}_{\mathrm{M}}, \mathrm{t}\right)=\mathrm{T}_{\mathrm{a}}+\mathrm{A} \exp \left(-\mathrm{z}_{\mathrm{M}} / \mathrm{D}\right) \sin \left(\omega \mathrm{t}-\mathrm{z}_{\mathrm{M}} / \mathrm{D}+\varphi\right)$

O seno tem valor máximo de 1 e valor mínimo de -1 ; ou seja, $1 \geq \sin \left(\omega t-z_{M} / D\right) \geq-1$. Logo, para qualquer valor do tempo $t$, ter-se-á, necessariamente, que a temperatura $T$ oscila entre dois extremos:

$T_{a}-A \exp \left(-z_{M} / D\right) \geq T\left(z_{M}, t\right) \geq T_{a}+A \exp \left(-z_{M} / D\right)$

Assim, para uma profundidade $\mathrm{z}_{\mathrm{M}}$, a temperatura pode afastar-se da média, $\mathrm{T}_{\mathrm{a}}$, no máximo em um certo valor $\Delta \mathrm{T}_{\mathrm{M}}\left({ }^{\circ} \mathrm{C}\right)$, dado por:

$\Delta \mathrm{T}_{\mathrm{M}}=\mathrm{A} \exp \left(-\mathrm{z}_{\mathrm{M}} / \mathrm{D}\right)$

Este valor $\Delta \mathrm{T}_{\mathrm{M}}$ informa em quanto se pode errar, no máximo, caso $\mathrm{T}(\mathrm{z}, \mathrm{t})$ seja aproximada para $\mathrm{T}_{\mathrm{a}}$.

Resolvendo a eq. [73] para $\mathrm{z}_{\mathrm{M}}$ :

$z_{M}=-D \ln \left(\frac{\Delta T_{M}}{A}\right)$ 
Fazendo $\Delta \mathrm{T}_{\mathrm{M}}=0,1{ }^{\circ} \mathrm{C}$ na eq. [74], pode-se calcular qual é a profundidade $\mathrm{z}_{\mathrm{m}}$ tal que, se temperatura $\mathrm{T}\left(\mathrm{z}_{\mathrm{M}}, \mathrm{t}\right)$ for aproximada como $\mathrm{T}_{\mathrm{a}}$, o erro em tal aproximação será somente de $0,1{ }^{\circ} \mathrm{C}$ ou menos. Isto obviamente implica que o erro será ainda menor para $\mathrm{z}>\mathrm{z}_{\mathrm{M}}$. $\mathrm{E}$ assim, de modo similar, caso se faça $\Delta \mathrm{T}_{\mathrm{M}}=0,01{ }^{\circ} \mathrm{C}$, ou igual a algum outro valor conveniente.

Esta definição de profundidade de penetração é útil porque leva em conta tanto a profundidade de amortecimento, D, como a amplitude, A. Além disso, o pesquisador tem a liberdade de definir a variação de temperatura, $\Delta \mathrm{T}_{\mathrm{M}}$, que considerar desprezível em uma dada situação. Suponhamos, por exemplo, que o pesquisador esteja trabalhando com valores de temperatura com três algarismos significativos, sendo dois deles corretos, e o terceiro, que mede décimos de ${ }^{\circ} \mathrm{C}$, duvidoso. Assim, variações de temperatura de centésimos de ${ }^{\circ} \mathrm{C}$ não seriam significativas. Pela eq. [74], seria possível calcular a profundidade $\mathrm{z}_{\mathrm{M}}$ em que $\Delta \mathrm{T}_{\mathrm{M}}=0,01{ }^{\circ} \mathrm{C}$. A partir desta profundidade, a temperatura seria de fato constante, quando se consideram os algarismos significativos somente até a casa de décimos.

Uma comparação de predições das eq. [10] e [66] foi feita calculando as profundidades de penetração das quatro ondas que aparecem nestas equações. As profundidades de penetração foram calculadas pela eq. [74], a partir dos parâmetros que aparecem nas eq. [10] e [66]: $D_{y}, D_{d}, D^{\prime}, D^{\prime}, A_{y}, A_{d}$ e B. Os valores de D' e D" aqui utilizados encontram-se nos resultados apresentados na seção 5.1. Considerou-se $\Delta \mathrm{T}_{\mathrm{m}}=0,1$ e $0,01{ }^{\circ} \mathrm{C}$.

\subsubsection{Erro quadrático médio}

Uma comparação de predições a partir das eq. [10] e [66] foi feita usando o pelo erro quadrático médio, ou EQM (Willmott, 1981):

$$
E Q M=\sqrt{\frac{1}{n} \sum_{i=1}^{n}\left(P_{i}-O_{i}\right)^{2}}
$$


No idioma inglês, Willmott (1981) refere-se a "root mean squared error", ou RMSE. Em português, a melhor tradução para este termo é erro quadrático médio (Rodrigues, 1970), aqui utilizada. Neste caso, $P_{i}$ foram valores de temperatura, $T(z, t)$, preditos a partir da eq. [10], e $\mathrm{O}_{\mathrm{i}}$ foram valores da eq. [66], de modo que a diferença $\left(\mathrm{P}_{\mathrm{i}}-\mathrm{O}_{\mathrm{i}}\right)$ que aparece na eq. [75] torna-se:

$$
\begin{aligned}
\mathrm{P}_{\mathrm{i}}-\mathrm{O}_{\mathrm{i}}=(\mathrm{B} / 2) \exp \left(-\mathrm{z} / \mathrm{D}^{\prime}\right) \sin \left(\omega^{\prime} \mathrm{t}_{\mathrm{i}}-\mathrm{z} / \mathrm{D}^{\prime}+\varphi_{\mathrm{d}}-\beta+\pi / 2\right)- \\
(\mathrm{B} / 2) \exp \left(-\mathrm{z} / \mathrm{D}^{\prime}\right) \sin \left(\omega^{\prime \prime} t_{\mathrm{i}}-\mathrm{z} / \mathrm{D}^{\prime}+\varphi_{\mathrm{d}}+\beta+\pi / 2\right)
\end{aligned}
$$

A profundidade $\mathrm{z}$ foi considerada constante para cada cálculo do EQM. Cálculos do $\mathrm{EQM}$ foram feitos para $\mathrm{z}=0,00,0,10,0,20,0,40$, e 1,00 m. A variável $\mathrm{t}_{\mathrm{i}}$ é dada por:

$\mathrm{t}_{\mathrm{i}}=\mathrm{t}_{0}+\mathrm{i} \Delta \mathrm{t}$

com $\mathrm{i}=1,2,3 \ldots \mathrm{n}$, e $\Delta \mathrm{t}$ é o passo temporal. Também existe, nesta equação, um valor $\mathrm{t}=\mathrm{t}_{0}$ quando começa o intervalo de tempo de comparação dos modelos, e um valor $\mathrm{t}=\mathrm{t}_{\mathrm{n}}$ quando este intervalo termina, de modo que, para $\mathrm{i}=\mathrm{n}$, a eq. [77] torna-se:

$\mathrm{t}_{\mathrm{n}}=\mathrm{t}_{0}+\mathrm{n} \Delta \mathrm{t}$

$\mathrm{O}$ intervalo de tempo é dado por $\mathrm{t}_{\mathrm{n}}-\mathrm{t}_{0}$, conforme a equação seguinte:

$\mathrm{t}_{\mathrm{n}}-\mathrm{t}_{0}=\mathrm{n} \Delta \mathrm{t}$

Assim, o valor de n na eq. [75] é:

$\mathrm{n}=\left(\mathrm{t}_{\mathrm{n}}-\mathrm{t}_{0}\right) / \Delta \mathrm{t}$ 
Nesta tese, a diferença $\mathrm{P}_{\mathrm{i}}-\mathrm{O}_{\mathrm{i}}$ foi calculada "de hora em hora", ou seja, para $\Delta \mathrm{t}=3600 \mathrm{~s}$, e o EQM foi calculado para os dias do ano, meses do ano, e para o ano todo. Assim, para calcular o EQM no decorrer de um ano inteiro, $n=8.760$; para meses inteiros, $n=672$, 720 ou 744; e para dias, $\mathrm{n}=24$. O produto $\mathrm{n} \Delta \mathrm{t}$ é uma constante, que tem o valor do intervalo de tempo a que se refere a comparação, que pode ser um ano, um mês, etc. Por exemplo, caso se queira saber como os modelos diferem-se nas previsões de temperatura sobre o mês de janeiro:

$\mathrm{t}_{0}=0, \mathrm{t}_{1}=3.600 \mathrm{~s}, \mathrm{t}_{\mathrm{n}}=2.678 .400 \mathrm{~s}, \mathrm{t}_{\mathrm{n}}-\mathrm{t}_{0}=2.678 .400 \mathrm{~s}, \mathrm{n}=744$. Para fevereiro:

$\mathrm{t}_{0}=2.678 .400 \mathrm{~s}, \mathrm{t}_{1}=2.682 .000 \mathrm{~s}, \mathrm{t}_{\mathrm{n}}=5.097 .600 \mathrm{~s}, \mathrm{t}_{\mathrm{n}}-\mathrm{t}_{0}=2.419 .200 \mathrm{~s}, \mathrm{n}=672$.

Também foi identificado o valor máximo do módulo de $\left(\mathrm{P}_{\mathrm{i}-\mathrm{O}_{\mathrm{i}}}\right)$, que indicaria a hora de maior discordância.

Observa-se que a eq. [76] não leva em conta parâmetros da onda anual, ou seja: $\mathrm{T}_{\mathrm{ay}}, \mathrm{A}_{\mathrm{y}}, \omega_{\mathrm{y}}$ e $\varphi_{\mathrm{y}}$, assim como não leva em conta um dos parâmetros da onda diária, $\mathrm{A}_{\mathrm{d}}$. Portanto, estes parâmetros não são necessários para o cálculo do EQM. Os valores de $\omega^{\prime}, \omega^{\prime}$, D' e D” aqui utilizados encontram-se nos resultados apresentados na seção 5.1.

\subsubsection{Erro quadrático médio na forma de uma integral}

Conforme mencionado no capítulo 2, é comum comparar-se um modelo com dados experimentais; ou então comparar-se dois modelos entre si, especialmente quando um dos modelos é analítico e o outro é numérico. Para tais comparações, uma ferramenta matemática numérica que pode ser utilizada é o EQM, dado pela eq. [75]. Nesta tese, o EQM foi usado para a comparação de dois modelos analíticos entre si, conforme mencionado na seção anterior. Entretanto, para uma comparação que envolve somente modelos analíticos, é também possível utilizar uma equação que define o EQM na forma de uma integral, ao invés de um somatório. Ou seja, é possível usar a eq. [86] abaixo, ao invés da eq. [75]. A seguir, será deduzida a equação do EQM na forma de uma integral.

Multiplicando o radicando da eq. [75] por $\Delta \mathrm{t} / \Delta \mathrm{t}$, esta torna-se: 
$E Q M=\sqrt{\frac{1}{n \Delta t} \sum_{i=1}^{n}\left[\left(P_{i}-O_{i}\right)^{2} \Delta t\right]}$

Observa-se que $P_{i}=P_{i}(t)$ e que $O_{i}=O_{i}(t)$, uma vez que, nesta tese, a eq. [75] foi usada considerando sempre uma profundidade constante, como mencionado na seção anterior. Assim, pode-se considerar o termo $\left(\mathrm{P}_{\mathrm{i}}-\mathrm{O}_{\mathrm{i}}\right)^{2}$ como uma função de $\mathrm{t}$, que será aqui chamada $g(t)$ :

$g(t)=\left[P_{i}(t)-O_{i}(t)\right]^{2}$

Considerando as eq. [82] e [79], a eq. [81] pode ser escrita como:

$E Q M=\sqrt{\left(t_{n}-t_{0}\right)^{-1} \sum_{i=1}^{n}[g(t) \Delta t]}$

Fazendo o limite para $\Delta t \rightarrow 0$, o lado direito da eq. [83] torna-se:

$E Q M=\sqrt{\left(t_{n}-t_{0}\right)^{-1} \int_{t 0}^{t n} g(t) d t}$

Será aqui suposto que existe a integral indefinida (também chamada de antiderivada ou função primitiva) da função $\mathrm{g}(\mathrm{t})$, a qual será aqui chamada $\mathrm{G}(\mathrm{t})$. Neste caso, a eq. [84] pode ser escrita como:

$E Q M=\sqrt{\left(t_{n}-t_{0}\right)^{-1}\left[G\left(t_{n}\right)-G\left(t_{0}\right)\right]}$ 
Para maior clareza, a partir de agora referir-se-á ao EQM na forma de integral pela sigla EQMI, sendo que EQM será usado somente para a forma de somatório. Assim, as eq. [84] e [85] serão respectivamente escritas como:

$$
\begin{aligned}
& \text { EQMI }=\sqrt{\left(t_{2}-t_{1}\right)^{-1} \int_{t 1}^{t 2} g(t) d t} \\
& E Q M I=\sqrt{\left(t_{2}-t_{1}\right)^{-1}\left[G\left(t_{2}\right)-G\left(t_{1}\right)\right]}
\end{aligned}
$$

onde os índices 0 e $\mathrm{n}$ foram convenientemente substituídos por 1 e 2 . Estes índices serão usados, a partir de agora, para significar os intervalos de integração, não como índices indicando termos de um somatório. A partir das eq. [82] e [76] , g(t) é dado por:

$$
\begin{array}{r}
g(t)=\left[(B / 2) \exp \left(-z / D^{\prime}\right) \sin \left(\omega^{\prime} t-z / D^{\prime}+\varphi_{d}-\beta+\pi / 2\right)-\right. \\
\left.(B / 2) \exp \left(-z / D^{\prime}\right) \sin \left(\omega^{\prime} t-z / D^{\prime}+\varphi_{d}+\beta+\pi / 2\right)\right]^{2}
\end{array}
$$

Como mencionado acima, o EQMI será utilizado para uma dada profundidade $\mathrm{z}$, tal que z passa a ser uma constante. Todos os termos constantes na eq. [88] podem ser agrupados, tal que esta pode ser escrita como:

$g(t)=\left[E^{\prime} \sin \left(\omega^{\prime} t+\varphi^{\prime}\right)-E^{\prime \prime} \sin \left(\omega^{\prime \prime} t+\varphi^{\prime}\right)\right]^{2}$

onde as constantes E', E”, $\varphi$ ’ e $\varphi$ ” são definidas como:

$$
\begin{aligned}
& E^{\prime}=(B / 2) \exp \left(-z / D^{\prime}\right) \\
& E^{\prime \prime}=(B / 2) \exp \left(-z / D^{\prime \prime}\right) \\
& \varphi^{\prime}=-z / D^{\prime}+\varphi_{d}-\beta+\pi / 2 \\
& \varphi^{\prime \prime}=-z / D^{\prime \prime}+\varphi_{d}+\beta+\pi / 2
\end{aligned}
$$


Resta agora calcular $G(t)$, para a função $g(t)$ dada pela eq [89]. A função $g(t)$ é um caso de "produto notável" da matemática fundamental, que pode ser imediatamente escrita como:

$$
g(t)=E^{\prime 2} \sin ^{2}\left(\omega^{\prime} t+\varphi^{\prime}\right)+E^{\prime \prime 2} \sin ^{2}\left(\omega^{\prime \prime} t+\varphi^{\prime \prime}\right)-2 E^{\prime} E^{\prime \prime} \sin \left(\omega^{\prime} t+\varphi^{\prime}\right) \cdot \sin \left(\omega^{\prime \prime} t+\varphi^{\prime \prime}\right)
$$

Pela eq. [94], observa-se que g(t) é igual a soma de três termos, cada um deles sendo o produto de duas senóides. Se $\mathrm{g}(\mathrm{t})$ pudesse ser escrita como a simples soma de senóides, sem envolver produtos, a solução do problema seria trivial, utilizando as seguintes integrais indefinidas:

$$
\begin{aligned}
& \int(\sin a x) d x=-\frac{1}{a} \cos a x \\
& \int(\cos a x) d x=\frac{1}{a} \sin a x
\end{aligned}
$$

Ora, pode-se transformar um produto de senóides em uma soma, usando a eq. [62]. Logo, este problema tem, de fato, uma solução trivial, ainda que trabalhosa do ponto de vista de manipulação algébrica, a qual será detalhadamente desenvolvida a seguir.

Para facilitar a manipulação algébrica, é conveniente escrever a eq. [94] como:

$$
g(t)=E^{\prime 2} \sin \left(a^{\prime}\right) \sin \left(a^{\prime}\right)+E^{\prime \prime 2} \sin \left(a^{\prime \prime}\right) \sin \left(a^{\prime \prime}\right)-2 E^{\prime} E^{\prime \prime} \sin \left(a^{\prime}\right) \cdot \sin \left(a^{\prime \prime}\right)
$$

onde as variáveis a' e a" são definidas como:

$$
\begin{aligned}
& a^{\prime}=\omega^{\prime} t+\varphi^{\prime} \\
& a^{\prime \prime}=\omega^{\prime \prime} t+\varphi^{\prime \prime}
\end{aligned}
$$


Utilizando a eq. [62], os três termos que compõem $g(t)$ podem respectivamente ser representados pelas três equações seguintes:

$$
\begin{aligned}
& E^{\prime 2} \sin \left(a^{\prime}\right) \sin \left(a^{\prime}\right)=E^{\prime 2}\left[\frac{\cos \left(a^{\prime}-a^{\prime}\right)-\cos \left(a^{\prime}+a^{\prime}\right)}{2}\right]=E^{\prime 2}\left[\frac{\cos (0)-\cos \left(2 a^{\prime}\right)}{2}\right] \\
& =E^{\prime 2}\left[\frac{1-\cos \left(2 a^{\prime}\right)}{2}\right]=0,5 E^{\prime 2}-0,5 E^{\prime 2} \cos \left(2 a^{\prime}\right) \\
& E^{\prime 2} \sin \left(a^{\prime \prime}\right) \sin \left(a^{\prime \prime}\right)=0,5 E^{\prime \prime 2}-0,5 E^{\prime \prime 2} \cos \left(2 a^{\prime \prime}\right) \\
& -2 E^{\prime} E^{\prime \prime} \sin \left(a^{\prime}\right) \sin \left(a^{\prime \prime}\right)=-2 E^{\prime} E^{\prime \prime}\left[\frac{\cos \left(a^{\prime}-a^{\prime \prime}\right)-\cos \left(a^{\prime}+a^{\prime \prime}\right)}{2}\right] \\
& =E^{\prime} E^{\prime \prime}\left[\cos \left(a^{\prime}+a^{\prime \prime}\right)-\cos \left(a^{\prime}-a^{\prime \prime}\right)\right]=E^{\prime} E^{\prime \prime} \cos \left(a^{\prime}+a^{\prime \prime}\right)-E^{\prime} E^{\prime \prime} \cos \left(a^{\prime}-a^{\prime \prime}\right)
\end{aligned}
$$

Com as eq. [100], [101] e [102], a eq. [97] torna-se:

$$
\begin{aligned}
& g(t)=0,5\left(E^{\prime 2}+E^{\prime 2}\right)-0,5 E^{\prime 2} \cos \left(2 a^{\prime}\right)-0,5 E^{\prime 2} \cos \left(2 a^{\prime \prime}\right)+ \\
& E^{\prime} E^{\prime \prime} \cos \left(a^{\prime}+a^{\prime \prime}\right)-E^{\prime} E^{\prime \prime} \cos \left(a^{\prime}-a^{\prime \prime}\right)
\end{aligned}
$$

Levando em conta as eq. [98] e [99], a eq. [103] torna-se

$$
\begin{aligned}
& g(t)=0,5\left(E^{\prime 2}+E^{\prime \prime 2}\right)-0,5 E^{\prime 2} \cos \left(2 \omega^{\prime} t+2 \varphi^{\prime}\right)-0,5 E^{\prime \prime 2} \cos \left(2 \omega^{\prime \prime} t+2 \varphi^{\prime \prime}\right) \\
& +E^{\prime} E^{\prime \prime} \cos \left[\left(\omega^{\prime}+\omega^{\prime \prime}\right) t+\left(\varphi^{\prime}+\varphi^{\prime \prime}\right)\right]-E^{\prime} E^{\prime \prime} \cos \left[\left(\omega^{\prime}-\omega^{\prime \prime}\right) t+\left(\varphi^{\prime}-\varphi^{\prime \prime}\right)\right]
\end{aligned}
$$

A eq. [104] é uma simples soma de senóides, como desejado, de modo que, aplicando a eq. [96], obtém-se a antiderivada procurada, G(t): 


$$
\begin{aligned}
& G(t)=0,5\left(E^{\prime 2}+E^{\prime \prime 2}\right) t-0,25 E^{\prime 2} \omega^{\prime-1} \sin \left(2 \omega^{\prime} t+2 \varphi^{\prime}\right)- \\
& 0,25 E^{\prime \prime 2} \omega^{\prime \prime}-1 \sin \left(2 \omega^{\prime \prime} t+2 \varphi^{\prime \prime}\right)+E^{\prime} E^{\prime \prime}\left(\omega^{\prime}+\omega^{\prime \prime}\right)^{-1} \sin \left[\left(\omega^{\prime}+\omega^{\prime \prime}\right) t+\left(\varphi^{\prime}+\varphi^{\prime \prime}\right)\right]- \\
& E^{\prime} E^{\prime \prime}\left(\omega^{\prime}-\omega^{\prime \prime}\right)^{-1} \sin \left[\left(\omega^{\prime}-\omega^{\prime \prime}\right) t+\left(\varphi^{\prime}-\varphi^{\prime \prime}\right)\right]
\end{aligned}
$$

A função $\mathrm{G}(\mathrm{t})$, dada pela eq. [105], pode, ainda, ser representada de outras maneiras. Por razões de simetria, pode ser escrita como:

$$
\begin{aligned}
& G(t)=0,5\left(E^{\prime 2}+E^{\prime \prime 2}\right) t-0,25 E^{\prime 2} \omega^{\prime-1} \sin \left(2 \omega^{\prime} t+2 \varphi^{\prime}\right)- \\
& 0,25 E^{\prime \prime 2} \omega^{\prime \prime} \sin \left(2 \omega^{\prime \prime} t+2 \varphi^{\prime \prime}\right)+E^{\prime} E^{\prime \prime} \omega_{p}^{-1} \sin \left(\omega_{p} t+\varphi_{p}\right)- \\
& E^{\prime} E^{\prime \prime} \omega_{n}^{-1} \sin \left(\omega_{n} t+\varphi_{n}\right)
\end{aligned}
$$

onde as variáveis $\omega_{\mathrm{p}}, \omega_{\mathrm{n}}, \varphi_{\mathrm{p}}$ e $\varphi_{\mathrm{n}}$ são definidas como:

$$
\begin{aligned}
& \omega_{\mathrm{p}}=\omega^{\prime}+\omega^{\prime \prime} \\
& \omega_{\mathrm{n}}=\omega^{\prime}-\omega^{\prime} \\
& \varphi_{\mathrm{p}}=\varphi^{\prime}+\varphi^{\prime \prime} \\
& \varphi_{\mathrm{n}}=\varphi^{\prime}-\varphi^{\prime \prime}
\end{aligned}
$$

Pode-se também escrever a eq. [105] como:

$$
\begin{aligned}
& G(t)=0,5\left(E^{\prime 2}+E^{\prime \prime 2}\right) t-0,25 E^{\prime 2} \omega^{\prime-1} \sin \left(2 \omega^{\prime} t+2 \varphi^{\prime}\right)- \\
& 0,25 E^{\prime \prime 2} \omega^{\prime \prime-1} \sin \left(2 \omega^{\prime \prime} t+2 \varphi^{\prime \prime}\right)+0,5 E^{\prime} E^{\prime \prime} \omega_{d}^{-1} \sin \left[2 \omega_{d} t+2 \varphi_{d}+\pi-\frac{z}{D^{\prime}}-\frac{z}{D^{\prime \prime}}\right]- \\
& 0,5 E^{\prime} E^{\prime \prime} \omega_{b}^{-1} \sin \left(-2 \omega_{b} t-2 \beta-\frac{z}{D^{\prime}}+\frac{z}{D^{\prime \prime}}\right)
\end{aligned}
$$

onde os termos $\omega^{\prime} \pm \omega^{\prime \prime}$ e $\varphi^{\prime} \pm \varphi$ ” foram eliminados pelas seguintes equações:

$$
\omega^{\prime}+\omega^{\prime \prime}=2 \omega_{\mathrm{d}}
$$




$$
\begin{aligned}
& \omega^{\prime}-\omega^{\prime \prime}=-2 \omega_{b} \\
& \varphi^{\prime}+\varphi^{\prime \prime}=2 \varphi_{d}+\pi-z / D^{\prime}-z / D^{\prime} \\
& \varphi^{\prime}-\varphi^{\prime \prime}=-2 \beta-z \text { / D' + z / D” }
\end{aligned}
$$

as quais foram obtidas a partir das eq. [67], [68], [92] e [93]. A eq. [111] tem a vantagem de permitir visualizar claramente uma certa contraposição entre os dois últimos termos, onde as variáveis relacionadas a variação de temperatura diária, $\omega_{\mathrm{d}} \mathrm{e} \varphi_{\mathrm{d}}$, são, de certa forma, substituídas pelas variáveis relacionadas à variação da amplitude diária, $\omega_{\mathrm{b}}$ e $\beta$. Entretanto, isto não significa que estas variáveis estejam realmente separadas em dois termos diferentes, uma vez que D' e D" são ambos função de $\omega_{d}$ e $\omega_{b}$. Logo, $\omega_{d}$ e $\omega_{b}$ estão relacionadas aos dois termos. Por outro lado, as fases $\varphi_{d}$ e $\beta$ estão claramente separadas.

Levando-se em conta a eq. [105], a eq. [87] torna-se:

$$
\begin{aligned}
& E Q M I=\left\{0,5\left(E^{\prime 2}+E^{\prime \prime 2}\right)-\frac{0,25 E^{\prime 2}}{\omega^{\prime}\left(t_{2}-t_{1}\right)}\left[\sin \left(2 \omega^{\prime} t_{2}+2 \varphi^{\prime}\right)-\sin \left(2 \omega^{\prime} t_{1}+2 \varphi^{\prime}\right)\right]-\right. \\
& \frac{0,25 E^{\prime \prime 2}}{\omega^{\prime \prime}\left(t_{2}-t_{1}\right)}\left[\sin \left(2 \omega^{\prime \prime} t_{2}+2 \varphi^{\prime \prime}\right)-\sin \left(2 \omega^{\prime \prime} t_{1}+2 \varphi^{\prime \prime}\right)\right]+ \\
& \frac{E^{\prime} E^{\prime \prime}}{\left(\omega^{\prime}+\omega^{\prime \prime}\right)\left(t_{2}-t_{1}\right)}\left\{\sin \left[\left(\omega^{\prime}+\omega^{\prime \prime}\right) t_{2}+\left(\varphi^{\prime}+\varphi^{\prime \prime}\right)\right]-\sin \left[\left(\omega^{\prime}+\omega^{\prime \prime}\right) t_{1}+\left(\varphi^{\prime}+\varphi^{\prime \prime}\right)\right]\right\}- \\
& \left.\frac{E^{\prime} E^{\prime \prime}}{\left(\omega^{\prime}-\omega^{\prime \prime}\right)\left(t_{2}-t_{1}\right)}\left\{\sin \left[\left(\omega^{\prime}-\omega^{\prime \prime}\right) t_{2}+\left(\varphi^{\prime}-\varphi^{\prime \prime}\right)\right]-\sin \left[\left(\omega^{\prime}-\omega^{\prime \prime}\right) t_{1}+\left(\varphi^{\prime}-\varphi^{\prime \prime}\right)\right]\right\}\right\}^{1 / 2}
\end{aligned}
$$

A forma de $\mathrm{G}(\mathrm{t})$ dada pela eq. [105] pode ser mais prática do que pelas eq. [106] ou [111] para ser inserida em uma planilha eletrônica. Para usar a eq. [105], inserem-se, inicialmente, os parâmetros $\mathrm{K}, \mathrm{B}, \omega_{\mathrm{b}}, \beta, \omega_{\mathrm{d}}$, e $\varphi_{\mathrm{d}}$. Inserem-se as eq. [67] e [68], para cálculo de $\omega^{\prime \prime}$ e $\omega^{\prime}$. Insere-se a eq. [5] para cálculo de $D_{d}$, D', e D”. Inserem-se as eq. [90], [91], [92], [93]. Inserem-se os valores de t que serão os limites de integração. Insere-se a eq. [105]. Finalmente, calcula-se o EQMI por meio da eq. [87]. A eq. [116] não precisa ser diretamente inserida, embora tenha sido indiretamente inserida pelo 
procedimento que acabou de ser descrito. $\mathrm{O}$ trabalho torna-se mais fácil se os nomes das variáveis forem atribuídos às células da planilha.

Da eq. [116] segue que:

$$
\begin{aligned}
& E Q M I^{2}=A_{1}-A_{2}\left[\sin \left(2 \omega^{\prime} t_{2}+2 \varphi^{\prime}\right)-\sin \left(2 \omega^{\prime} t_{1}+2 \varphi^{\prime}\right)\right]- \\
& A_{3}\left[\sin \left(2 \omega^{\prime \prime} t_{2}+2 \varphi^{\prime \prime}\right)-\sin \left(2 \omega^{\prime \prime} t_{1}+2 \varphi^{\prime \prime}\right)\right]+ \\
& A_{4}\left\{\sin \left[\left(\omega^{\prime}+\omega^{\prime \prime}\right) t_{2}+\left(\varphi^{\prime}+\varphi^{\prime \prime}\right)\right]-\sin \left[\left(\omega^{\prime}+\omega^{\prime \prime}\right) t_{1}+\left(\varphi^{\prime}+\varphi^{\prime \prime}\right)\right]\right\}- \\
& A_{5}\left\{\sin \left[\left(\omega^{\prime}-\omega^{\prime \prime}\right) t_{2}+\left(\varphi^{\prime}-\varphi^{\prime \prime}\right)\right]-\sin \left[\left(\omega^{\prime}-\omega^{\prime \prime}\right) t_{1}+\left(\varphi^{\prime}-\varphi^{\prime \prime}\right)\right]\right\}
\end{aligned}
$$

com

$$
\begin{aligned}
& A_{1}=0,5\left(E^{\prime 2}+E^{\prime \prime 2}\right) \\
& A_{2}=\frac{-0,25 E^{\prime 2}}{\omega^{\prime} \Delta t} \\
& A_{3}=\frac{-0,25 E^{\prime \prime 2}}{\omega^{\prime \prime} \Delta t} \\
& A_{4}=\frac{E^{\prime} E^{\prime \prime}}{\left(\omega^{\prime}+\omega^{\prime \prime}\right) \Delta t} \\
& A_{5}=\frac{-E^{\prime} E^{\prime \prime}}{\left(\omega^{\prime}-\omega^{\prime \prime}\right) \Delta t}
\end{aligned}
$$

com $\Delta \mathrm{t}=\left(\mathrm{t}_{2}-\mathrm{t}_{1}\right)$. Observa-se que, a partir de agora, $\Delta \mathrm{t}$ será usado com o significado de intervalo de integração, não de passo temporal.

Percebe-se, pela eq. [117] , que EQMI ${ }^{2}$ é igual a soma de cinco termos, cada um deles uma senóide, cuja amplitude é $\mathrm{A}_{\mathrm{i}}, \mathrm{i}=1,2, \ldots 5$. O primeiro termo é uma senóide com fase e freqüência angular nulas.

É interessante comparar a ordem de grandeza das variáveis $\mathrm{A}_{\mathrm{i}}$. Deve-se recordar que o valor do seno está limitado entre +1 e -1 . Logo, a soma de dois senos, que aparece dentro dos colchetes e dentro das chaves, está limitada entre +2 e -2 . Assim, a ordem de grandeza de cada um dos cinco termos de EQMI ${ }^{2}$ é igual às amplitudes $\mathrm{A}_{\mathrm{i}}$. Se alguma 
destas amplitudes for desprezível em relação às demais, o respectivo termo poderá ser desprezado, tal que a eq. [116] poderá ser simplificada.

Considerando as eq. [5], [90] e [91], observa-se que as variáveis $K, \omega^{\prime}, \omega^{\prime \prime}$ e $\Delta t$ são suficientes para determinar as amplitudes $\mathrm{A}_{\mathrm{i}}$. Considerar-se-á como os valores de $\omega$ ' e $\omega$ ', afetam os valores das amplitudes $E_{\mathrm{i}}$. Valores de $\omega$ ' e $\omega$ " diferem em menos de $1 \%$, conforme resultados apresentados na seção 5.1, sendo ambos muito próximos a $\omega_{\mathrm{d}}$. Em conseqüência, E' e E” também estarão muito próximos entre si. Para uma situação em que isto se verifica, pode-se fazer $\omega^{\prime}=\omega^{\prime \prime}=\omega_{\mathrm{d}}$, e $\mathrm{E}^{\prime}=\mathrm{E}^{\prime \prime}=\mathrm{E}_{\mathrm{d}}$, como uma aproximação, tal que as amplitudes $A_{i}, i=1,2, \ldots 4$, podem ser escritas do modo que segue:

$$
\begin{aligned}
& \mathrm{A}_{1}=\mathrm{E}_{\mathrm{d}}^{2} \\
& \mathrm{~A}_{2}=[-1 /(8 \pi)] \mathrm{E}_{\mathrm{d}}^{2}\left(\mathrm{~T}_{\mathrm{d}} / \Delta \mathrm{t}\right) \\
& \mathrm{A}_{3}=\mathrm{A}_{2} \\
& \mathrm{~A}_{4}=[1 /(4 \pi)] \mathrm{E}_{\mathrm{d}}^{2}\left(\mathrm{~T}_{\mathrm{d}} / \Delta \mathrm{t}\right)
\end{aligned}
$$

onde se eliminou a freqüência angular, $\omega$, nas eq. [118]-[121] e introduziu-se os períodos, T (s), lembrando que $\omega=2 \pi / \mathrm{T}$. A aproximação $\omega^{\prime}=\omega^{\prime \prime}=\omega$ não pode ser feita para $\mathrm{A}_{5}$, pois a diferença de dois valores aproximadamente iguais pode será um valor muito pequeno; como esta diferença aparece no denominador, é necessário utilizar seu valor exato, dado pela eq. [113], tal que a eq. [122] torna-se:

$$
\mathrm{A}_{5}=[-1 /(4 \pi)] \mathrm{E}_{\mathrm{d}}^{2}\left(\mathrm{~T}_{\mathrm{b}} / \Delta \mathrm{t}\right)
$$

Observa-se, pelas eq. [123]-[126], que, para $\Delta t=T_{d}, A_{2}, A_{3}$ e $A_{4}$ terão valores abaixo de $A_{1}$ em pelo menos uma ordem de grandeza. Assim, para $\Delta t>1$ dia, os termos segundo, terceiro e quarto podem ser desprezados por que são muito menores do que o primeiro. Desprezando estes termos menores, a eq. [116] torna-se: 
$\mathrm{EQMI}=$

$E_{d}\left\{1-[1 /(4 \pi)]\left(T_{b} / \Delta t\right)\left\{\sin \left[\left(\omega^{\prime}-\omega^{\prime \prime}\right) t_{2}+\left(\varphi^{\prime}-\varphi^{\prime \prime}\right)\right]-\sin \left[\left(\omega^{\prime}-\omega^{\prime \prime}\right) t_{1}+\left(\varphi^{\prime}-\varphi^{\prime \prime}\right)\right]\right\}\right\}^{1 / 2}$

Observa-se, pela eq. [128], que para $\Delta t=T_{b}, A_{5}$ terá valores abaixo de $A_{1}$ em uma ordem de grandeza. Assim, para $\Delta \mathrm{t}=1$ ano, o quinto termo pode ser desprezado, de modo que a eq. [128] torna-se:

$\mathrm{EQMI}=\mathrm{E}_{\mathrm{d}}$

Por meio da eq. [90] ou [91], juntamente com a eq. [5], e considerando o valor numérico de $\mathrm{T}_{\mathrm{d}}$, a eq. [129] torna-se:

$$
\begin{aligned}
\operatorname{EQMI}=(\mathrm{B} / 2) \exp \left(-\mathrm{z} / \mathrm{D}_{\mathrm{d}}\right)=\frac{B}{2} \exp \left(-\frac{\mathrm{z}}{\sqrt{K}} \sqrt{\frac{\pi}{T_{d}}}\right) \\
=(\mathrm{B} / 2) \exp \left(-0,006 \mathrm{z} \mathrm{s}^{-1 / 2} \mathrm{~K}^{-1 / 2}\right)
\end{aligned}
$$

Para $\mathrm{z}=0$ tem-se que:

$\mathrm{EQMI}=(\mathrm{B} / 2)$

o que é bastante razoável, mostrando consistência dos resultados analíticos obtidos até aqui. A eq. [131] informa que o EQMI anual na superfície é metade da amplitude B. Por outro lado, dois modelos estudados diferem no máximo em B, e no mínimo em zero, como se observa comparando as eq. [9] e [61], que representam as eq. [10] e [66] para o caso particular em que $\mathrm{z}=0$. É intuitivamente razoável que a discordância média, ao longo de um período completo, seja a média entre as discordâncias mínima e máxima, ou seja, a média entre B e zero, que é B/2. 
Para $\mathrm{z} \rightarrow \infty$ tem-se que:

$\mathrm{EQMI}=0$

o que é consistente com os resultados da seção 5.1, que indicam que, para $\mathrm{z}>0,6 \mathrm{~m}$, as eq. [10] e [66] tornam-se praticamente as mesmas, dadas pela eq. [135]. Se as equações tornam-se iguais, então o EQMI deveria de fato ser zero para z suficientemente grande. Isto está em perfeita concordância com a eq. [132], a qual informa que as eq. [10] e [66] devem fornecer previsões praticamente iguais para uma profundidade $\mathrm{z}$ de valor suficientemente elevado.

Por meio das eq. [112]-[115], a eq. [128] pode ser escrita como:

$$
\begin{aligned}
& \mathrm{EQMI}=\mathrm{E}_{\mathrm{d}}\left\{1+[1 /(4 \pi)]\left(\mathrm{T}_{\mathrm{b}} / \Delta \mathrm{t}\right)\left[\sin \left(-2 \omega_{\mathrm{b}} \mathrm{t}_{2}-2 \beta-\mathrm{z} / \mathrm{D}^{\prime}+\mathrm{z} / \mathrm{D}^{\prime \prime}\right)-\right.\right. \\
& \left.\left.\sin \left(-2 \omega_{\mathrm{b}} \mathrm{t}_{1}-2 \beta-\mathrm{z} / \mathrm{D}^{\prime}+\mathrm{z} / \mathrm{D}^{\prime \prime}\right)\right]\right\}^{1 / 2}
\end{aligned}
$$

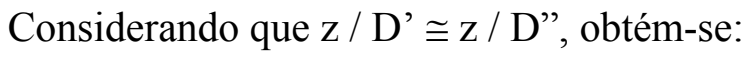

$$
\mathrm{EQMI}=\mathrm{E}_{\mathrm{d}}\left\{1+[1 /(4 \pi)]\left(\mathrm{T}_{\mathrm{b}} / \Delta \mathrm{t}\right)\left[\sin \left(-2 \omega_{\mathrm{b}} \mathrm{t}_{2}-2 \beta\right)-\sin \left(-2 \omega_{\mathrm{b}} \mathrm{t}_{1}-2 \beta\right)\right]\right\}^{1 / 2}
$$

Observa-se que o valor máximo do fator representado pelos colchetes depende somente de $t_{1}$ e de $t_{2} ;$ não depende de $z$. Assim, se os valores de $\Delta t$ representarem os meses do ano, pode-se prever que, para qualquer profundidade, os valores máximos e mínimos do RMSI sempre ocorrerão nos mesmos meses, independentemente da profundidade.

Resumindo as simplificações feitas, pode-se dizer que, para o cálculo do EQMI, com $\Delta t>1$ dia, os termos segundo, terceiro e quarto podem ser desprezados porque são muito menores do que o primeiro. O quinto termo pode ser desprezado para cálculos do EQMI anual, mas deve ser considerado para cálculos $\Delta \mathrm{t}=1$ mês ou menos. É importante enfatizar que, antes de aplicar as eq. [128] e [129] para uma situação particular, é necessário confirmar, com base em dados de temperatura, a validade da condição 
$\omega_{\mathrm{d}}>>\omega_{\mathrm{b}}$. Isto consistiria em uma limitação das eq. [128] e [129]. Por outro lado, é razoável supor que os fenômenos periódicos, causadores da variação de amplitude diária ao longo do ano, dependam das estações do ano, e tenham freqüência angular anual ou algumas vezes este valor. Como exemplo, podem-se citar as três localidades estudadas por Elias et al. (2004), com $\omega_{\mathrm{b}}=\omega_{\mathrm{y}}, 2 \omega_{\mathrm{y}}$ e $\omega_{\mathrm{y}}$, conforme o Apêndice 1. É concebível que o mesmo ocorra para dados de outras localidades, e que as eq. [128] e [129] tenham, portanto, uma aplicação ampla.

Pela eq. [130], vê-se que o EQMI tomado em um ano somente depende de K, B e $\mathrm{z}$, não dependendo das fases $\beta$ e $\varphi_{\mathrm{d}}$. Depende, ainda, da condição $\omega_{\mathrm{d}}>\omega_{\mathrm{b}}$, mas não depende de valores numéricos de $\omega_{\mathrm{b}}$, uma vez que esta condição esteja satisfeita.

Pode-se questionar se, para $\Delta \mathrm{t}<1 \mathrm{dia}$, os termos segundo, terceiro e quarto do $\mathrm{EQMI}^{2}$ seriam ou não desprezíveis em comparação com o quinto. Se isto ocorresse, então estes termos poderiam ser desprezados para qualquer valor de $\Delta \mathrm{t}$, sendo somente necessários o primeiro e o quinto termo. Infelizmente, não parece haver uma resposta simples para isto. $\mathrm{A}_{5}$ é uma fração cujo numerador tem ordem de grandeza igual à dos numeradores das frações $\mathrm{A}_{2}, \mathrm{~A}_{3}$ e $\mathrm{A}_{4}$, porém com denominador duas ordens de grandeza menor. Logo $A_{2}, A_{3}$ e $A_{4}$ são desprezíveis em relação a $A_{1}$. Entretanto, isto não implica necessariamente que o quinto termo de $\mathrm{EQMI}^{2}$ seja maior do que os três anteriores. É concebível que a diferença de senos (valor entre as chaves) fosse próximo de zero para este termo, para $\Delta \mathrm{t}<1$ dia. De fato, isto poderia ocorrer quando $\Delta \mathrm{t}$ fosse pequeno, ou seja, quando $t_{1}$ e $t_{2}$ estivessem próximos. A freqüência angular é muito pequena; logo, se $\mathrm{t}_{1}$ e $\mathrm{t}_{2}$ estivessem próximos, os respectivos senos também poderão estar muito próximos. Logo a diferença entre os dois senos poderia ser muito pequena, de modo a compensar o fato de que $\mathrm{A}_{5}$ é muito maior do que $\mathrm{A}_{2}, \mathrm{~A}_{3}$ e $\mathrm{A}_{4}$. Não é óbvio, portanto, por meio destas considerações analíticas, que estes termos possam ser desprezados para $\Delta \mathrm{t}<1$ dia.

As eq. [116], [128] e [129] foram aqui usadas para comparar os dois modelos analíticos de temperatura do perfil do solo, dados pelas eq. [10] e [66], como uma alternativa à eq. [75]. Limites de integração, $t_{2}$ e $t_{1}$, utilizados na simulação encontramse na Tabela 1 , bem como os valores de $\Delta \mathrm{t}$, para o cálculo de EQMI para cada mês e 
para o ano todo. Valores diários de EQMI também foram calculados, mas os limites de integração não aparecem na Tabela 1 . Parâmetros usados foram exatamente os mesmos que no caso do EQM na forma de um somatório, explicado na seção anterior.

Tabela 1. Limites de integração, $t_{2}$ e $t_{1}$, e intervalos de integração, $\Delta t=t_{2}-t_{1}$, utilizados no cálculo do erro quadrático médio na forma de uma integral, eq. [116] e [128]
$t_{2}(s)$
$\mathrm{t}_{1}(\mathrm{~s})$
$\Delta \mathrm{t}(\mathrm{s})$

\begin{tabular}{llll}
\hline & & & \\
janeiro & $2,68 \times 10^{6}$ & 0 & $2,68 \times 10^{6}$ \\
fevereiro & $5,10 \times 10^{6}$ & $2,68 \times 10^{6}$ & $2,42 \times 10^{6}$ \\
março & $7,78 \times 10^{6}$ & $5,10 \times 10^{6}$ & $2,68 \times 10^{6}$ \\
abril & $1,04 \times 10^{7}$ & $7,78 \times 10^{6}$ & $2,59 \times 10^{6}$ \\
maio & $1,30 \times 10^{7}$ & $1,04 \times 10^{7}$ & $2,68 \times 10^{6}$ \\
junho & $1,56 \times 10^{7}$ & $1,30 \times 10^{7}$ & $2,59 \times 10^{6}$ \\
julho & $1,83 \times 10^{7}$ & $1,56 \times 10^{7}$ & $2,68 \times 10^{6}$ \\
agosto & $2,10 \times 10^{7}$ & $1,83 \times 10^{7}$ & $2,68 \times 10^{6}$ \\
setembro & $2,36 \times 10^{7}$ & $2,10 \times 10^{7}$ & $2,59 \times 10^{6}$ \\
outubro & $2,63 \times 10^{7}$ & $2,36 \times 10^{7}$ & $2,68 \times 10^{6}$ \\
novembro & $2,89 \times 10^{7}$ & $2,63 \times 10^{7}$ & $2,59 \times 10^{6}$ \\
dezembro & $3,15 \times 10^{7}$ & $2,89 \times 10^{7}$ & $2,68 \times 10^{6}$ \\
ano & $3,15 \times 10^{7}$ & 0 & $3,15 \times 10^{7}$ \\
\hline
\end{tabular}




\section{RESULTADOS E DISCUSSÃO}

\subsection{Profundidade de amortecimento}

Obteve-se $\quad \omega^{\prime}=7,25 \quad 10^{-5} \mathrm{rad} \mathrm{s}^{-1}, \quad \omega^{\prime \prime}=7,29 \quad 10^{-5} \mathrm{rad} \mathrm{s}^{-1}, \quad \mathrm{D}^{\prime}=0,124 \mathrm{~m}$, D” = 0,123 m. Estes valores mostram que $\omega$ ' e $\omega$ ” estão muito próximos de $\omega_{\mathrm{d}}$, enquanto que D' e D" estão muito próximos de $\mathrm{D}_{\mathrm{d}}$. Este resultado é bastante aceitável, pelo motivo a seguir. Considerando que $\omega_{\mathrm{y}}=\omega_{\mathrm{b}}$, e que $\omega_{\mathrm{d}}>>\omega_{\mathrm{y}} \sim \omega_{\mathrm{b}}$, segue que $\omega_{\mathrm{d}}>>\omega_{\mathrm{b}}$. Em conseqüência, $\omega_{\mathrm{d}} \pm \omega_{\mathrm{b}} \cong \omega_{\mathrm{d}}$, o que implica que $\omega^{\prime} \cong \omega_{\mathrm{d}}$ e $\omega^{\prime \prime} \cong \omega_{\mathrm{d}}$. As variáveis $\omega_{\mathrm{d}}, \omega$ ' e $\omega$ " terão aproximadamente os mesmos valores numéricos, sempre que verificar-se que $\omega_{\mathrm{d}}>>\omega_{\mathrm{b}}$. Então, devido a eq. [5], valores numéricos de $\mathrm{D}_{\mathrm{d}}$, D' e D” devem ser, também, aproximadamente os mesmos.

O novo modelo aqui apresentado, dado pela eq. [66], introduz duas ondas adicionais, que têm praticamente a mesma profundidade de amortecimento da onda diária. A amplitude de tais ondas, a uma profundidade de cerca de $0,60 \mathrm{~m}$, seria reduzida a menos de $1 \%$ da amplitude na superfície, conforme seção 3.3. Assim, a correção introduzida pelo novo modelo somente seria importante próximo à superfície. Para profundidades maiores do que $0,60 \mathrm{~m}$, somente a onda anual seria importante. Apenas os dois primeiros termos do lado direito das eq. [10] e [66] são importantes para $\mathrm{z}>0,60 \mathrm{~m}$, de tal forma que estas equações tornam-se praticamente as mesmas para tais profundidades. Assim, para $z>0,60 \mathrm{~m}$, tanto a eq. [10] como a eq. [66] se reduzem a:

$T(z, t)=T_{a y}+A_{y} \exp \left(-z / D_{y}\right) \sin \left(\omega_{y} t-z / D_{y}+\varphi_{y}\right)$ 


\subsection{Profundidade de penetração}

Para $\Delta \mathrm{T}_{\mathrm{m}}=0,01{ }^{\circ} \mathrm{C}$, as profundidades de penetração envolvidas têm valores: $\mathrm{z}_{\mathrm{M}, \mathrm{y}}=13,85 \mathrm{~m}, \mathrm{z}_{\mathrm{M}, \mathrm{d}}=0,82 \mathrm{~m}, \mathrm{z}_{\mathrm{M}}{ }^{\prime}=\mathrm{z}_{\mathrm{M}}{ }^{\prime \prime}=0,56 \mathrm{~m}$. Para $\Delta \mathrm{T}_{\mathrm{m}}=0,1{ }^{\circ} \mathrm{C}$, têm valores: $\mathrm{z}_{\mathrm{M}, \mathrm{y}}=8,41 \mathrm{~m}, \mathrm{z}_{\mathrm{M}, \mathrm{d}}=0,53 \mathrm{~m}, \mathrm{z}_{\mathrm{M}}{ }^{\prime}=\mathrm{z}_{\mathrm{M}}{ }^{\prime}{ }^{\prime}=0,28 \mathrm{~m}$.

Embora as duas ondas adicionais tenham a mesma profundidade de amortecimento da onda diária, elas possuem profundidade de penetração consideravelmente menor. Isto se deve à menor amplitude das ondas adicionais, que não é levada em conta no cálculo da profundidade de amortecimento. Assim, o conceito de profundidade de penetração, aqui sugerido, parece ser útil para comparação de modelos.

\subsection{Comparação pelo EQM}

Resultados da comparação, usando eq. [76], encontram-se na tabela 2. 
Tabela 2. Médias mensais de valores de erro quadrático médio (EQM), em ${ }^{\circ} \mathrm{C}$, para quatro profundidades no solo, em São Paulo, Brasil. Médias anuais dos valores do EQM, para cada profundidade, são mostradas na última linha. Valores de EQM foram obtidos pela eq. [75], para comparar as previsões dos dois modelos analíticos, dados pelas eq. [10] e [66]

\begin{tabular}{cccccc}
\hline & \multicolumn{5}{c}{ Profundidade $(\mathrm{m})$} \\
\hline Mês & 0,00 & 0,10 & 0,20 & 0,40 & 1,00 \\
01 & 0,61 & 0,27 & 0,12 & 0,02 & 0,00 \\
02 & 0,40 & 0,18 & 0,08 & 0,02 & 0,00 \\
03 & 0,13 & 0,06 & 0,03 & 0,01 & 0,00 \\
04 & 0,27 & 0,12 & 0,05 & 0,01 & 0,00 \\
05 & 0,53 & 0,24 & 0,11 & 0,02 & 0,00 \\
06 & 0,66 & 0,29 & 0,13 & 0,03 & 0,00 \\
07 & 0,61 & 0,27 & 0,12 & 0,02 & 0,00 \\
08 & 0,40 & 0,18 & 0,08 & 0,02 & 0,00 \\
09 & 0,12 & 0,06 & 0,02 & 0,00 & 0,00 \\
10 & 0,28 & 0,13 & 0,06 & 0,01 & 0,00 \\
11 & 0,54 & 0,24 & 0,11 & 0,02 & 0,00 \\
12 & 0,66 & 0,29 & 0,13 & 0,03 & 0,00 \\
Ano & 0,48 & 0,21 & 0,09 & 0,02 & 0,00 \\
\hline
\end{tabular}

Encontrou-se $\mathrm{EQM}=0,21{ }^{\circ} \mathrm{C}$ para o ano inteiro, em z $=0,10 \mathrm{~m}$, de tal forma que a correção global introduzida pela equação nova é pequena. Entretanto, valores de EQM para dias individuais podem ser maiores. Para $\mathrm{z}=0,10 \mathrm{~m}$, o valor diário máximo é $\mathrm{EQM}=0,30{ }^{\circ} \mathrm{C}$. Para horas individuais, o valor horário máximo do módulo de $\left(\mathrm{P}_{\mathrm{i}}-\mathrm{O}_{\mathrm{i}}\right)$ é de $0,42{ }^{\circ} \mathrm{C}$. Valores de EQM para meses inteiros são consideráveis para junho e dezembro, em $\mathrm{z}=0,10 \mathrm{~m}$, embora muito pequenos para março e setembro. Observa-se também que valores de EQM são muito pequenos para $\mathrm{z}=0,40 \mathrm{~m}$ e desprezíveis para 
$\mathrm{z}=1,00 \mathrm{~m}$, para todos os meses, como esperado a partir das considerações preliminares acima, baseadas nos valores das profundidades de amortecimento e de penetração.

Para os dados estudados, as diferenças entre os dois modelos são, em todos os casos, pequenas, pois tem valores máximos de décimos de graus. Os modelos analíticos aqui tratados envolvem muitas aproximações, como foi mencionado nos capítulos 1 e 2 desta tese. A correção aqui apresentada trata de corrigir apenas uma das aproximações usadas no modelo tradicional, ou seja, de considerar a amplitude diária constante. As demais aproximações continuam a ser usadas também no modelo aqui proposto. Assim, a correção aqui apresentada pode ser encoberta pelos erros resultantes das demais aproximações. Não é possível aqui concluir definitivamente sobre este ponto. Entretanto, a única informação adicional requerida para aplicar a equação nova são parâmetros sobre a variação temporal da amplitude diária. Se tal informação estiver disponível, seria preferível utilizar o modelo corrigido, por pouco que fosse o aumento de exatidão nos resultados. Não haveria qualquer motivo para ignorar dados existentes e deixar de aumentar a exatidão das previsões, ainda que fosse pequeno o aumento, considerando que a aplicação do novo modelo não exige sofisticação consideravelmente maior do que o modelo tradicional. Há somente um acréscimo de dois termos exponencial-senoidais. Assim, a utilização do presente modelo não leva a prejuízos, podendo somente trazer vantagens. Por outro lado, para os casos em que a obtenção de dados adicionais seja trabalhosa, não é possível concluir, com base nos resultados aqui apresentados, se valeria ou não à pena tentar obtê-los para utilizar a nova equação. Esta limitação do presente estudo deve ficar clara para o leitor.

É concebível que trabalhos futuros, aplicando o novo modelo a dados de temperatura de outras regiões do planeta, venham a encontrar uma diferença maior entre os dois modelos, caso seja verificada uma maior variação temporal da amplitude diária, ou seja, maiores valores de B. Modelos analíticos são difíceis de se obter, e não devem ser desprezados. Assim, a divulgação científica deste modelo torna-se relevante, para que possa ser utilizado futuramente, caso uma situação de grande utilidade seja encontrada, mesmo que nenhuma fosse identificada neste momento. 
O EQM foi sugerido por Willmott (1981) para comparação de um modelo com dados experimentais. Também foi aplicado por Cichota et al. (2004) para comparar dois modelos entre si, sendo um modelo de diferenças finitas, e o outro analítico. Nesta tese tratou-se, entre outras coisas, de uma outra forma de aplicação do EQM: comparação de dois modelos analíticos. Os resultados aqui apresentados na seção indicam que informações interessantes podem ser extraídas a partir desta nova aplicação do EQM. 


\subsection{Comparação pelo EQMI}

Valores obtidos para o EQMI, utilizando as eq. [116] e [128], foram os mesmos que pelo EQM constantes na Tabela 2, de modo que torna-se desnecessário apresentar outra tabela. Além disso, a máxima discordância diária também foi a mesma que pelo EQM. O cálculo do EQMI global para um ano todo, pela eq. [129], também resultou em valores iguais aos da Tabela 2, para todas as profundidades. Os meses de máxima discordância permaneceram os mesmos para qualquer profundidade, junho e dezembro. Os meses de mínima discordância permaneceram os mesmos para qualquer profundidade, março e setembro. Isto mostra, novamente, concordância entre o EQM e o EQMI. Estes resultados confirmam que as aproximações e previsões feitas na seção 4.3.4 estão corretas. É importante frisar que o método para comparação de modelos pelo EQMI é válido somente quando ambos os modelos comparados são analíticos, o que constitui em uma grande limitação do EQMI. Além disso, é necessário encontrar a antiderivada da função $\mathrm{g}(\mathrm{t})$, dada pela eq. [82], o que nem sempre é fácil, ou mesmo possível. No caso particular da comparação das eq. [10] e [66], isto foi possível, mas ainda há outras desvantagens. Pelo EQMI, é mais complexo calcular a hora de maior discordância do que pelo EQM. Seria necessária calcular a integral definida para cada intervalo de uma hora, e então localizar o valor máximo. O EQM permite trabalhar-se diretamente com comparações de hora em hora. Cada integral definida é substituída por uma simples diferença. Por outro lado, o EQMI é vantajoso para avaliar a discordância global ao longo de períodos maiores, como um ano ou um mês, como na construção da Tabela 2. Cada valor da Tabela 2 é calculado mais rapidamente, exigindo menor recurso computacional. Outra vantagem é que os valores obtidos são, em princípio, mais exatos, por substituir-se um somatório por uma integral. Entretanto, neste estudo observou-se pequeno aumento na exatidão, de modo que os resultados foram iguais até a segunda casa decimal, ambos representados pela Tabela 2.

É concebível que trabalhos futuros, em que seja necessária a comparação de outros modelos analíticos envolvendo processos de transferência no solo, possam utilizar o conceito de EQMI. De modo similar ao mencionado na seção anterior, é 
necessário enfatizar o seguinte: a obtenção de um procedimento analítico capaz de substituir um procedimento numérico nem sempre é possível; um tal procedimento não deve ser desprezado quando obtido. Assim, a divulgação científica deste método de comparação de modelos, pelo EQMI, parece também relevante, para potencial utilização futuramente. 


\section{CONCLUSÕES}

A equação do fluxo de calor, eq. [1], foi aqui resolvida para a condição de contorno de superfície que leva em conta a variação temporal da amplitude diária, [60], obtendo-se uma nova equação para o perfil de temperatura do solo, eq. [66]. Esta nova equação não aumenta consideravelmente o nível de complexidade do problema estudado, quando comparado com a equação tradicional para o perfil de temperatura do solo, eq. [10]. Do ponto de vista educacional, qualquer estudante ou pesquisador que possa compreender e aplicar a equação tradicional, também poderia compreender e aplicar a nova. O número de termos exponencial-senoidais duplica, mas isto não representa aumento considerável nas dificuldades de cálculo.

Também foi aqui desenvolvida a definição de profundidade de penetração de uma onda de temperatura, dada pela eq. [74]. Esta definição pode ser útil na comparação de modelos, uma vez que leva em conta a amplitude da onda, além da profundidade de amortecimento. Esta nova definição, juntamente com o conhecido conceito de profundidade de amortecimento, permitiu uma comparação preliminar entre as duas equações para o perfil de temperatura do solo, eq. [10] e [66], mostrando que ambas as equações fornecem predições praticamente iguais para profundidades superiores a $0,60 \mathrm{~m}$.

Os dois modelos foram comparados por meio de valores de erro quadrático médio (EQM), eq. [76]. A comparação mostra que a nova equação para o perfil de temperatura do solo fornece resultados diferentes da equação tradicional, conforme Tabela 2. Para os dados estudados, esta diferença é muito pequena. Entretanto, a única informação adicional requerida para aplicar equação nova é a informação de variação temporal da amplitude diária. Desta forma, pode-se sugerir que a nova equação seja 
preferida, quando esta informação esteja facilmente disponível a partir de dados experimentais. É concebível que trabalhos futuros, utilizando dados de temperatura de outras regiões, venham a encontrar uma diferença maior entre os dois modelos.

Além da profundidade de penetração, ainda outro conceito foi aqui desenvolvido, que pode ser útil na comparação de modelos analíticos. Este foi o conceito de EQM na forma de uma integral, aqui chamado de EQMI, em que o somatório, que aparece na equação tradicional do EQM, é substituído por uma integração, conforme as eq. [86] e [87]. Foi aqui encontrada a função primitiva necessária para realizar a integração analiticamente, eq. [105], levando à uma equação completa para o EQMI, eq. [116], e duas formas simplificadas da mesma, eq. [128] e [129]. Valores obtidos pelo EQMI são praticamente os mesmos que os obtidos pelo EQM. Uma sugestão para um trabalho futuro seria tentar aplicar o EQMI para comparação de outros modelos analíticos envolvendo processos de transferência no solo.

No desenvolvimento desta tese, o processo de tentar aperfeiçoar modelos existentes gerou uma grande motivação para compreendê-los. Desta forma, um trabalho deste tipo tem grande valor educacional para o próprio pesquisador que realiza a modelagem. O resultado final, uma vez publicado em periódicos especializados, pode ser útil para outros pesquisadores. Entretanto, o processo que ocorre, durante o trabalho de modelagem, é particularmente útil para o próprio pesquisador, independentemente do resultado final, por propiciar melhor compreensão dos processos físicos envolvidos. A importância da modelagem como um processo educacional foi enfatizada por Passioura (1996), e foi particularmente observada no decorrer desta tese. 


\section{REFERÊNCIAS BIBLIOGRÁFICAS}

ABRAMOWITZ, M.; STEGUN, I.A. Handbook of mathematical functions with formulas, graphs and mathematical tables. Washington: U.S. Gov. Print. Office, 1972. 1046p. (Applied Mathematics Series, 55)

ANLAUF, R.; PING, L.Y. Simulation of simple one-dimensional transport processes. In: RICHTER, J. (Ed.) Models for processes in the soil: programs and exercises. Cremlingen-Destedt: Catena Verlag, 1990. cap.2, p.9-29.

BOYCE, W.E.; DIPRIMA, R.C. Equações diferenciais elementares e problemas de valores de contorno. 3.ed. Trad. de A. C. C. de Carvalho e C. A. A. de Carvalho. Rio de Janeiro: Guanabara Dois, 1965. 587p.

CAMPBELL, S.C.; NORMAN, J.M.. An introduction to environmental biophysics. 2.ed. New York: Springer-Verlag New York, Inc., 1998. 286p.

CARSLAW, H.S.; JAEGER, J.C. Conduction of heat in solids. 2.ed. Oxford: Oxford University Press, 1959. 510p.

CICHOTA, R.; ELIAS, E.A.; DE JONG VAN LIER, Q. Finite-difference model for soil heat transfer: test of validity by comparing numerical and analytical solutions. Environmental Modeling \& Software, v.19, p.495-506, 2004. 
DE VRIES, D.A. Thermal properties of soils. In: VAN WIJK, W.R. (Ed.) Physics of plant environment. Amsterdam: North Holland Publ., 1963. cap.7, p.210-235.

ELIAS, E.A.; CICHOTA, R.; TORRIANI, H.H.; DE JONG VAN LIER, Q. Analytical soil-temperature model: correction for temporal variation of daily amplitude. Soil Science Society of America Journal, v.68, p.784-788, 2004.

GUIDORIZZI, H.L. Um curso de cálculo. 2.ed. Rio de Janeiro: LTC - Livros Técnicos e Científicos, 1995, 586p.

HANKS, R.J. Applied soil physics. 2.ed. New York: Springer-Verlag New York, Inc., 1992. 176p.

HANKS, R.J.; AUSTIN, D.D.; ONDRECHEN, W.T. Soil temperature estimation by a numerical method. Soil Science Society of America Proceedings, v.35, p.665-677, 1971.

HORTON, R.; CHUNG, S. Soil heat flow. In: HANKS, J.; RITCHIE, J.T. (Ed.). Modeling plant and soil systems. Madison: American Society of Agronomy; Crop Science Society of America; Soil Science Society of America, 1991. cap.17, p.397438.

HORTON, R.; AGUIRRE-LUNA, O.; WIERENGA, P.J. Observed and predicted twodimensional soil temperature distributions under a row crop. Soil Science Society of America Journal, v.48, p.1147-1152, 1984.

HORTON, R.; WIERENGA, P.J.; NIELSEN, D.R. Evaluation of methods for determining the apparent thermal diffusivity of soil near the surface. Soil Science Society of America Journal, v.47, p.25-32, 1983. 
JACKSON, R.D.; KIRKHAM D. Method of measurement of the real thermal diffusivity of moist soil. Soil Science Society of America Proceedings, v22, p.479-482, 1958.

JURY, W.A.; GARDNER, W.R.; GARDNER, W.H.. Soil physics. New York: John Wiley, 1991. 328p.

KIRKHAM, D.; POWERS, W.L. Advanced soil physics. New York: Wiley Interscience, 1972. 534p.

KLUITENBERG, G.J.; HORTON, R. Analytical solution for two-dimensional heat conduction beneath a partial surface mulch. Soil Science Society of America Journal, v.54, p.1197-1206, 1990.

MASSMAN, W.J. Periodic temperature variations in an inhomogeneous soil: a comparison of approximate and exact analytical expressions. Soil Science, v.155, p.331-338, 1993.

MILLY, P.C.D. Moisture and heat transport in hysteretic, inhomogeneous porous media: a matric head-based formulation and a numerical model. Water Resources Research, v.18, p.489-498, 1982.

MOROIZUMI T.; HORINO H. The effects of tillage on soil temperature and soil water. Soil Science, v.167, p.548-559, 2002.

NAKSHABANDI, G.A.; KONKE, H. Thermal conductivity and diffusivity of soils as related to moisture tension and other physical properties. Agricultural Meteorology, v.2, p.271-279, 1965. 
PARTON, W.J.; LOGAN, J.A. A model for diurnal variation in soil and air temperature. Agricultural Meteorology, v.23, p.205-216, 1981.

PASSIOURA, J.B. Simulation models: science, snake oil, education, or engineering? Agronomy Journal, v.88, p.690-694, 1996.

PREVEDELLO, C.L. Física do solo com problemas resolvidos. Curitiba: SaleswardDiscovery, 1996. 446p.

REICHARDT, K.; TIMM, L.C. Solo, planta e atmosfera: conceitos, processos e aplicações. Barueri: Manole, 2004. 478p.

RICHTER, J. The soil as a reactor. Cremlingen: Catena Verlag, 1987. 192p.

SEN, A.; SRIVASTAVA, M. Regression analysis. New York: Spring-Verlag, 1990. $347 p$.

SINCLAIR, T.R.; SELIGMAN, N.G. Crop modeling: from infancy to maturity. Agronomy Journal. v.88, p.698-704, 1996.

STEENHUIS, T.S.; WALTER, M.F. Will drainage increase spring soil temperatures in cool and humid climates? Transactions of the ASAE, v.29, n. 6, p.1641-1645, 1986.

THUNHOLM, B. Methods for estimating thermal diffusivity of the subsoil based on annual temperature variations. Swedish Journal of Agricultural Research, v. 18, p.179-184, 1988. 
VAN WIJK, W.R. Physics of plant environment. Amsterdam: North Holland Publ. 1963.

VAN WIJK, W.R.; DE VRIES, D.A. Periodic temperature variations in a homogenous soil. In: VAN WIJK, W.R. (Ed.) Physics of plant environment. Amsterdam: North Holland Publishing Company, 1963. cap.4, p.102-143.

WIERENGA, P.J.; DE WIT, C.T. Simulation of heat transfer in soils. Soil Science Society of America Proceedings, v.34, p.845-848, 1970.

WILlMOTT, C.J. On the validations of models. Physical Geography, v.2, n.2, p.184-194, 1981.

ZACHARIAS, S.; HEATWOLE, C.D; CAOKLEY, C.W. Robust quantitative techniques for validating pesticide transport models. Transactions of the ASAE, v.39, p.47-54, 1996. 
APÊNDICES 


\section{APÊNDICE 1}

Esta tese tratou do aperfeiçoamento do modelo analítico para a temperatura do perfil do solo descrito por Van Wijk \& de Vries (1963), dado pela eq. [10]. Este aperfeiçoamento pode ser útil quando são conhecidos os parâmetros da eq. [11], que descreve a variação temporal da amplitude diária. Neste apêndice será descrito o ajuste de dados de temperatura à eq. [11], para a obtenção de tais parâmetros, feito por Elias et al. (2004).

Dados de temperatura utilizados foram médias de séries de dez anos, obtidos das seguintes fontes:

(i) IAG - Estação Meteorológica, Instituto de Astronomia, Geofísica e Ciências Atmosféricas, USP (Universidade de São Paulo), São Paulo, SP, Brasil. Latitude:

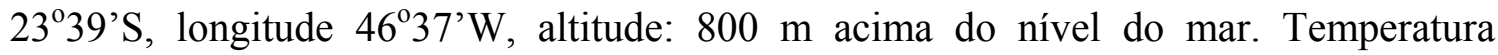
superficial do solo foi medida com termômetros de mercúrio.

(ii) AWS - Automatic Weather Station, Atmospheric Science, Division of Environmental and Life Sciences, Macquarie University, Sydney, Australia. Latitude: $33^{\circ} 46^{\prime} \mathrm{S}$, longitude: $151^{\circ} 7^{\prime} \mathrm{E}$, altitude: 55,0 $\mathrm{m}$ acima do nível do mar. Temperatura superficial do solo foi medida pelo equipamento "Campbell Scientific, Inc. (Logan, UT) TCAV Averaging Soil Thermocouple Probe". Dados disponíveis diretamente da Internet: http://atmos.es.mq.edu.au/ aws2/variables.html (verificado em 9 de abril de 2004).

(iii) IAC - Estação Meteorológica, Instituto Agronômico, Ribeirão Preto, SP, Brasil. Latitude: $21^{\circ} 11^{\prime} \mathrm{S}$, longitude: $47^{\circ} 48^{\prime} \mathrm{W}$, altitude: $621 \mathrm{~m}$ acima do nível do mar. Temperatura superficial do solo foi medida com termômetros de mercúrio a $2 \mathrm{~cm}$ de profundidade. 
A eq. [11] foi ajustada aos dados pelo método dos mínimos quadrados (Sen \& Srivastava, 1990), a fim de obter-se os parâmetros $A_{d}, B, \omega_{b}$ e $\beta$, para cada uma das três séries de dados. Para este ajuste, médias aritméticas mensais de amplitudes diárias dos dados observados foram usadas, ao invés de valores diários, de forma que o ajuste foi feito para doze pontos, e não 365. Parâmetros resultantes do ajuste de dados à eq. [11] encontram-se na Tabela 3.

Tabela 3. Parâmetros ajustados para descrever variação temporal de amplitude diária da temperatura superficial (São Paulo e Sydney) e próxima da superfície (Ribeirão Preto) do solo, eq. [11], em três localidades

\begin{tabular}{lccc}
\hline Parâmetro & São Paulo & Sydney & Ribeirão Preto \\
\hline $\mathrm{A}_{\mathrm{d}},{ }^{\circ} \mathrm{C}$ & 7,49 & 3,17 & 7,10 \\
$\mathrm{~B},{ }^{\circ} \mathrm{C}$ & 0,95 & 0,35 & 0,66 \\
$\omega_{\mathrm{b}}, \mathrm{rad} \mathrm{s}^{-1}$ & $1,99 \times 10^{-7}$ & $3,99 \times 10^{-7}$ & $1,99 \times 10^{-7}$ \\
$\beta, \mathrm{rad}$ & 1,73 & 0,36 & 2,23 \\
\hline
\end{tabular}

Fonte: Elias et al. (2004)

O modelo dado pela eq. [11] foi comparado com dados experimentais pelo erro quadrático médio, ou EQM (Willmott, 1981), dado pela eq [75]. Neste caso, os valores $\mathrm{O}_{\mathrm{i}}$ são as médias aritméticas mensais de amplitudes diárias dos dados observados, tal que $\mathrm{n}=12$; $\mathrm{P}_{\mathrm{i}}$ são os valores preditos pelo modelo, ou seja, $\mathrm{P}_{\mathrm{i}}=\mathrm{C}(\mathrm{t})$, onde $\mathrm{C}(\mathrm{t})$ é dado pela eq. [11].

O modelo linear, que considera a amplitude diária constante, também foi comparado com dados experimentais, usando a eq [75] de willmott; porém, neste caso, resultados preditos, $\mathrm{P}_{\mathrm{i}}$, têm o valor $\mathrm{P}_{\mathrm{i}}=\mathrm{A}_{\mathrm{d}}=$ constante. Esta constante $\mathrm{A}_{\mathrm{d}}$ é obtida pela média dos 12 valores de $\mathrm{O}_{\mathrm{i}}$ acima mencionados. Por outro lado, a constante $\mathrm{A}_{\mathrm{d}}$ foi também obtida pelo ajuste da eq. [11]. Resultados são apresentados na tabela 4. 
Observa-se que os valores de EQM são menores para o modelo senoidal. Assim, pode-se concluir que, para os dados estudados, a eq. [11] é uma melhor descrição da amplitude diária da temperatura da superfície dos solos estudados do que um valor constante, $\mathrm{A}_{\mathrm{d}}$. Isto exemplifica a vantagem de utilizar-se a eq. [11] para estes solos, ao invés de simplesmente presumir-se um ajuste linear.

Por outro lado, mesmo que o ajuste linear tivesse se mostrado adequado, não haveria nenhum prejuízo em utilizar-se a eq. [11]; teria sido encontrado simplesmente $\mathrm{B}=0$.

Tabela 4. Valores do erro quadrático médio $(\mathrm{EQM})$ em ${ }^{\circ} \mathrm{C}$, obtidos a partir da comparação da amplitude diária de dados de temperatura do solo com o modelo senoidal, $C(t)$ da eq. [75], e também com o valor médio e constante, $A_{d}$, em três localidades

\begin{tabular}{lllc}
\hline Modelo & São Paulo & Sydney & Ribeirão Preto \\
\hline senoidal & 0,50 & 0,29 & 0,33 \\
valor médio & 0,83 & 0,38 & 0,57 \\
\hline
\end{tabular}

Fonte: Elias et al. (2004)

Resultados encontrados por Elias et al. (2004) parecem coerentes. É razoável supor que esta função $\mathrm{C}(\mathrm{t})$ seja periódica, pois $\mathrm{T}$ depende de fenômenos periódicos, relacionados com as estações do ano. A maneira mais simples de descrever uma função periódica é por uma função senoidal. Assim, seria razoável supor que, em um caso geral, a amplitude diária pudesse ser descrita por uma função senoidal do tempo. Pode-se, portanto, tentar ajustar dados de amplitude diária a uma função senoidal, ao invés de simplesmente calcular-se a média anual, como é feito quando são usadas as eq. [9] e [10]. Em um caso particular, é possível encontrar-se $B=0$, de forma que $C(t)=A_{d}$. Neste caso, C poderia ser descrita corretamente como uma constante. A vantagem de descrever $\mathrm{C}$ pela eq. [11] é que esta representaria uma situação geral, que incluiria o caso particular em que $\mathrm{C}$ é de fato constante. Na modelagem de Van Wijk \& de Vries 
(1963), ao assumir-se C como uma constante, é implicitamente assumido um ajuste linear a dados de $\mathrm{C}(\mathrm{t})$, o que nem sempre é o melhor ajuste; logo se generaliza um caso particular. $\mathrm{Na}$ modelagem dada pela eq. [11], não é necessário fazer tal suposição de linearidade. $\mathrm{O}$ ajuste à eq. [11] pode ser feito facilmente, sempre que dados da amplitude diária estejam disponíveis, de modo a encontrar-se, a partir dos próprios dados, se o melhor ajuste é linear ou não, sem necessidade de assumir-se isto. A tentativa de ajustar dados à eq. [11] nunca poderá levar a um pior ajuste do que o linear; no máximo poderá levar à um ajuste linear, uma vez que este é um caso particular da função senoidal. Assim, nunca haverá desvantagem em utilizar a eq. [11] ao invés de um ajuste linear, podendo somente haver vantagens. 


\section{APÊNDICE 2}

Esta tese tratou do aperfeiçoamento do modelo analítico para a temperatura do perfil do solo descrito por Van Wijk \& de Vries (1963), dado pela eq. [10]. Uma das utilidades de modelos analíticos, como foi mencionado nos capítulos 1 e 2 desta tese, é a de permitir testes preliminares de modelos numéricos. Neste apêndice será descrito, ainda que superficialmente, um modelo de diferenças finitas, e será comentada a vantagem de tais testes preliminares.

Um modelo de fluxo de calor no solo pode ser desenvolvido dividindo-se o solo em $n$ camadas de espessura $\Delta z$. Considerando que no tempo t a temperatura $\left(T_{z, t}\right)$ e umidade $\left(\theta_{z, t}\right)$ de cada camada $z$ sejam conhecidas e que estas se mantêm constantes durante um intervalo de tempo de tamanho $\Delta \mathrm{t}$, para as camadas $\mathrm{z}=2$ a $\mathrm{z}=\mathrm{n}-1$ a temperatura no intervalo seguinte $\left(\mathrm{T}_{\mathrm{z}, \mathrm{t}+1}\right)$ é calculada baseando-se na temperatura da camada imediatamente acima $\left(T_{z-1, t}\right)$ e imediatamente abaixo $\left(T_{z+1, t}\right)$ da camada $z$ com base no seguinte:

A densidade de fluxo de energia entre a camada z-1 e z no tempo t é calculada pela equação de Fourier, eq. [12], que é escrita como:

$$
J_{(z-1, z), t}=\bar{\lambda}_{e(z-1, z), t} \frac{T_{z, t}-T_{z-1, t}}{\Delta z}
$$

onde 


$$
\bar{\lambda}_{e(z-1, z), t}=\frac{\lambda_{e}(\theta)_{z-1, t}+\lambda_{e}(\theta)_{z, t}}{2}
$$

sendo $\lambda_{\mathrm{e}}(\theta)_{\mathrm{z}-1, \mathrm{t}}$ e $\lambda_{\mathrm{e}}(\theta)_{\mathrm{z}, \mathrm{t}}$ a condutividade térmica, função da umidade, no tempo $\mathrm{t}$ nas profundidades z-1 e z, respectivamente. A densidade de fluxo de energia entre a camada $\mathrm{z}$ e $\mathrm{z}+1$ pode ser calculada de forma análoga.

A partir das densidades de fluxo $J_{(z, z+1), t}$ e $J_{(z-1, z), t}$ e conhecendo-se o capacidade térmica volumétrica da camada $\mathrm{z}, \mathrm{C}_{\mathrm{z}}\left(\mathrm{J} \mathrm{m}^{-3} \mathrm{~K}^{-1}\right)$ calcula-se a temperatura da camada $\mathrm{z}$ no próximo intervalo de tempo $\mathrm{T}_{\mathrm{z}, \mathrm{t}+1}$ pelo princípio da conservação de energia:

$$
T_{z, t+1}=T_{z, t}+\frac{J_{(z, z+1), t}-J_{(z-1, z), t}}{C_{z} \Delta z} \Delta t
$$

Essa equação é análoga a eq. [1], no entanto para diferenças finitas. A eq. [138] é mais flexível do que a eq. [1], pois a eq. [138] não exige que a condutividade térmica seja independente de $z$, nem que capacidade térmica volumétrica do solo seja constante no tempo e em profundidade. Além da eq. [1] ser menos flexível, sua solução analítica pode exigir ainda mais suposições; por exemplo, sobre as condições de contorno do problema a ser resolvido, ou exigir que a condutividade térmica seja constante no tempo. Nada disso é exigido no caso da eq. [138]; logo ela pode representar melhor situações arbitrárias de campo.

Para a primeira camada $(z=1)$, a densidade de fluxo no lado superior (superfície do solo) pode ser estimada em função da temperatura da camada e dados sobre o saldo de radiação. Para a última camada $(z=n)$, a densidade de fluxo de energia no lado inferior pode ser considerada nula. Essa aproximação torna-se válida desde que essa camada se encontra numa profundidade suficientemente grande. Para permitir a suposição da constância da temperatura ao longo de uma camada de espessura $\Delta z$ e de um intervalo de tempo $\Delta t$, esses devem ser escolhidos suficientemente pequenos. 
Modelos de diferenças finitas precisam ser validados, por meio de comparação com dados experimentais, e também comparando com modelos analíticos. Há uma grande vantagem em fazer testes preliminares de um modelo numérico, comparando este com um modelo analítico. Isto sempre que existir um modelo analítico; no caso da temperatura do perfil do solo, como foi visto, existe. Quando o modelo numérico é comparado com o analítico, ambos podem receber o mesmo "input" (ou quase o mesmo, como discutido por Cichota et al., 2004). Assim, qualquer diferença no "output" pode ser atribuída a uma falha na aproximação das diferenças finitas. Por outro lado, se o modelo numérico fosse somente comparado com dados experimentais, sem fazer o teste preliminar, e discordância fosse encontrada, haveria dúvida sobre a causa da discordância. Seria ela causada porque o nível de complexidade do modelo numérico é insuficiente para descrever a situação de campo de interesse? Seria causada por uma falha conceitual no modelo numérico? Ou seria simplesmente causada por erros de cálculo resultantes da aproximação das diferenças finitas? O teste preliminar é a melhor maneira de responder a última pergunta, daí sua importância. Apesar desta importância, a maioria dos autores consultados fazem este teste de uma maneira simplificada, principalmente por "data-plots". Cichota et al. (2004) indicam como testes preliminares podem ser feitos de maneira mais exaustiva. Para a comparação de modelos, utilizaram principalmente o erro quadrático médio (Willmott, 1981). Observam que um modelo numérico pode ser ainda melhor do que aparenta. Pequenas discordâncias encontradas entre o modelo numérico e o analítico podem ser apenas aparentes, e não reais, sendo causadas por falhas metodológicas quanto ao teste. Observa-se, portanto, a importância dos modelos analíticos como uma ferramenta na validação dos modelos numéricos. 